\title{
¿Hail-Detection Algorithm for the GPM Core Observatory Satellite Sensors $\mathscr{O}$
}

\author{
Kamil Mroz, ${ }^{\mathrm{a}}$ Alessandro Battaglia, ${ }^{\mathrm{a}, \mathrm{b}}$ Timothy J. Lang, ${ }^{\mathrm{c}}$ Daniel J. Cecil, ${ }^{\mathrm{c}}$ \\ SIMONE TANELLI, ${ }^{\mathrm{d}}$ FREDERIC TRIDON ${ }^{\mathrm{b}}$ \\ ${ }^{\mathrm{a}}$ National Centre for Earth Observation, University of Leicester, Leicester, United Kingdom \\ ${ }^{\mathrm{b}}$ Earth Observation Science, Department of Physics and Astronomy, University of Leicester, Leicester, \\ United Kingdom \\ ${ }^{\mathrm{c}}$ NASA Marshall Space Flight Center, Huntsville, Alabama \\ ${ }^{\mathrm{d}}$ Jet Propulsion Laboratory, California Institute of Technology, Pasadena, California
}

(Manuscript received 18 November 2016, in final form 31 March 2017)

\begin{abstract}
By exploiting an abundant number of extreme storms observed simultaneously by the Global Precipitation Measurement (GPM) mission Core Observatory satellite's suite of sensors and by the groundbased S-band Next Generation Weather Radar (NEXRAD) network over the continental United States, proxies for the identification of hail are developed from the GPM Core Observatory satellite observables. The full capabilities of the GPM Core Observatory are tested by analyzing more than 20 observables and adopting the hydrometeor classification on the basis of ground-based polarimetric measurements being truth. The proxies have been tested using the critical success index (CSI) as a verification measure. The haildetection algorithm that is based on the mean Ku-band reflectivity in the mixed-phase layer performs the best of all considered proxies (CSI of $45 \%$ ). Outside the dual-frequency precipitation radar swath, the polarization-corrected temperature at $18.7 \mathrm{GHz}$ shows the greatest potential for hail detection among all GPM Microwave Imager channels (CSI of $26 \%$ at a threshold value of $261 \mathrm{~K}$ ). When dual-variable proxies are considered, the combination involving the mixed-phase reflectivity values at both $\mathrm{Ku}$ and $\mathrm{Ka}$ bands outperforms all of the other proxies, with a CSI of $49 \%$. The best-performing radar-radiometer algorithm is based on the mixed-phase reflectivity at $\mathrm{Ku}$ band and on the brightness temperature (TB) at $10.7 \mathrm{GHz}$ (CSI of $46 \%$ ). When only radiometric data are available, the algorithm that is based on the TBs at 36.6 and $166 \mathrm{GHz}$ is the most efficient, with a CSI of $27.5 \%$.
\end{abstract}

\section{Introduction}

The destructive nature of hailstorms motivates the scientific community to deliver and refine more and more precise hail-detection algorithms. Proxies derived from ground-based observations are routinely used for extreme-weather prediction, with the history of hail detection dating back in time to the middle of

Denotes content that is immediately available upon publication as open access.

Supplemental information related to this paper is available at the Journals Online website: http://dx.doi.org/10.1175/ JAMC-D-16-0368.s1.

Corresponding author: Kamil Mroz, km357@le.ac.uk the twentieth century, when ground-based radars were incorporated by weather services around the world.

In the late 1950s, the analysis performed by Donaldson (1959) in the New England region of the United States with 300 precipitation reports and measurements from $\mathrm{X}$-band radar showed that the occurrence of hail is strongly related to the storm height and to the maximum reflectivity values. Both of these factors directly depend on the updraft speed, because hail forms only when an upward speed of air masses within a storm exceeds hailstone terminal velocity, which increases with size (Heymsfield 1978; Heymsfield and Wright 2014). According to Donaldson's findings, $50 \%$ of storm cells that exceed the 50-dBZ X-band reflectivity-factor value and at the same

This article is licensed under a Creative Commons Attribution 4.0 license (http://creativecommons. org/licenses/by/4.0/). 
time are higher than $12.2 \mathrm{~km}$ bear hailstones. When only the height of the storm cell is considered, he showed that hail occurs in $50 \%$ of cells that are taller than $14 \mathrm{~km}$.

Twenty years later, Waldvogel et al. (1979) used the maximum height of $45-\mathrm{dB} Z$ echo at $\mathrm{X}$ band as a measure of the updraft speed. They analyzed the radar data from 195 convective storms over Switzerland and showed that all hail-bearing cells produce a signal of $45 \mathrm{dBZ}$ at least $1.4 \mathrm{~km}$ above the freezing level. On the other hand, only $50 \%$ of storms that satisfy this criterion contain hail.

Over the years, lower-frequency radars have become more popular since they are less prone to attenuation, and new severe-weather detection techniques were developed. Auer (1994) suggested using radar reflectivity data at $\mathrm{S}$ band and the cloud-top temperature derived from either satellite imagery or sounding analysis to provide discrimination between heavy rain and hail shafts. His study, conducted in New Zealand, showed that $91 \%$ of hail-bearing storms satisfied the condition

$$
2.6 Z_{e}(\mathrm{dBZ})+\mathrm{TB}\left({ }^{\circ} \mathrm{C}\right) \geq 85,
$$

where TB is brightness temperature. Moreover, this proxy led to a false alarm in only $12 \%$ of cases. His findings were not confirmed in other places, and so such a relation may be strongly regime/region dependent.

Another hail-detection algorithm that is based on S-band observations was proposed by Kitzmiller et al. (1995). They claimed that there is a clear correspondence between the intensity of rain and total ice water content in the vertical column; therefore, the vertically integrated liquid was proposed as an indication of strong convection. Their hail-detection algorithm that is based on this measure was tested over the continental United States and performed with a success index of $40 \%$.

Witt et al. (1998) proposed a hail-detection algorithm that is based on S-band radar data from the NEXRAD network and on the temperature profile. With these two pieces of information, they defined a severe-hail index that was used as a proxy not only for detecting hail but also for its sizing. Their algorithm was tested on a dataset comprising 31 days in various regions of the continental United States. The overall detection capabilities are very high — the algorithm being able to identify $78 \%$ of hailstorms but at the same time suffering from a high number of false alarms (69\%).

The most recent hail-detection proxies not only incorporate radar reflectivity data and temperature profiles but fully exploit the polarimetric capabilities of modern radar systems. An example of such a state-ofthe-art algorithm was proposed by Heinselman and Ryzhkov (2006). Its capabilities were tested on data collected mostly during the Joint Polarimetric Experiment
(JPOLE; 28 April-13 June 2003), during which it performed incredibly well, with the probability of detection reaching $100 \%$ and the false-alarm rate as low as $11 \%$. The algorithm was validated for only four cases, and therefore these results must be used with caution.

Depue et al. (2007) proposed a very simple algorithm that utilizes radar reflectivity and differential reflectivity values only. Validation data on hail characteristics (diameter, density, etc.) were obtained from general public surveys for 12 hailstorms observed by the Colorado State University-University of Chicago-Illinois State Water Survey S-band polarimetric radar. Ground hail reports were compared with low-elevation-angle radar measurements. It was shown that the algorithm correctly identified $89 \%$ of the regions for which large hail was reported and that false alarms were issued in only $15 \%$ of cases, which resulted in a critical success index of $77 \%$.

Another polarimetric hail-detection algorithm was proposed by Ortega et al. (2016), in which the results of theoretical simulations investigating the polarimetric radar properties of melting hail were exploited to develop a hail size discrimination algorithm (HSDA). The HSDA is based on a fuzzy-logic scheme and uses radar reflectivity, differential reflectivity, cross-correlation coefficient, and information on the melting-level height to distinguish small, large, and giant hail. The algorithm performance was extensively tested using radar data from the NEXRAD network and high-resolution hail reports obtained during the Severe Hazard Analysis and Verification Experiment (SHAVE); for details, see Ortega et al. (2009). The HSDA demonstrated a probability of detection of $59 \%$, a false-alarm ratio of $14 \%$, and a critical success index of $54 \%$.

In parallel to the evolution of ground-based weather radars, spaceborne observing systems have been developed. Despite the limitations that arise from the generally coarser resolutions, satellite measurements are capable of providing information about weather in remote places that are not covered by ground-based stations; therefore, they are perfect tools for monitoring climate globally. Current spaceborne systems are not limited to radiometric measurements only but deploy radars as well-for example, the satellites of the GPM and CloudSat missions. For overviews of science goals and technical specifications of these two missions, see Hou et al. (2014) and Stephens et al. (2002), respectively.

Cecil (2009) used 8 years of passive measurements from the Tropical Rainfall Measuring Mission (TRMM) satellite and hail ground reports in the United States to assess the correlation between measured TB depressions and hailstorm occurrences. He also tested hail-detection capabilities of the Precipitation Radar on board the same satellite. According to his findings, $74 \%$ of storms that 
produce a $49.1-\mathrm{dBZ}$ echo and $43 \%$ of storms that produce a $43.1-\mathrm{dB} Z$ echo at $9-\mathrm{km}$ altitude are associated with hail reports on the ground. In addition, he showed that $79 \%$ of storms whose $\mathrm{TB}$ at $36.6 \mathrm{GHz}$ is lower than $180 \mathrm{~K}$ are associated with hailfall. These radiometric results were generalized for providing a global distribution of severe hailstorms by Cecil and Blankenship (2012). To extend results validated in the subtropical land to the other climatological regimes, regional scaling of the measured TBs was used. The description of this procedure is detailed in Cecil (2011).

A similar statistical approach using collocated satellite and surface hail reports over the continental United States was proposed by Ferraro et al. (2015) for the Advanced Microwave Sounding Unit (AMSU) measurements. Using surface observations as a reference, the algorithm detects approximately $40 \%$ of hail occurrences using simple thresholds on all five AMSU-B TBs:

$$
\begin{aligned}
\mathrm{TB}_{89} & \leq 228.2 \mathrm{~K}, \mathrm{~TB}_{150} \leq 206.9 \mathrm{~K}, \mathrm{~TB}_{183 \pm 1} \leq 211.1 \mathrm{~K}, \\
\mathrm{~TB}_{183.3 \pm 3} & \leq 204.6 \mathrm{~K}, \text { and } \mathrm{TB}_{183 \pm 7} \leq 200.5 \mathrm{~K} .
\end{aligned}
$$

These optimal threshold values on the TB at highfrequency channels differ considerably from those proposed here for the GPM Microwave Imager (GMI; see Table 1 in the online supplemental material). These discrepancies arise mainly from a different resolution: the AMSU-B unit operates in a cross-track $\left( \pm 50^{\circ}\right)$ mode, making 90 observations. The field of view is circular at $16 \mathrm{~km}$ at nadir and increases to an oval shape of $27 \mathrm{~km} \times 54 \mathrm{~km}$ at the edge of the scan (Ferraro et al. 2015), whereas the footprint of the GMI at $89 \mathrm{GHz}$ is only $7.2 \mathrm{~km} \times 4.4 \mathrm{~km}$ (Hou et al. 2014). The analysis performed by Musil et al. (1991) during the 1981 Cooperative Convective Precipitation Experiment (CCOPE) field project revealed that approximately one-half of the observed updraft-downdraft regions were no wider than $1.5-2 \mathrm{~km}$, that the largest encountered updraft was $15 \mathrm{~km}$ wide, and that the largest encountered downdraft was $8 \mathrm{~km}$ wide. It implies that more extreme TB values are observed by the instrument with a higher resolution.

Leppert and Cecil (2015) recently used a hydrometeorclassification algorithm that is based on S-band polarimetric measurements as a source of validation data for determining the signatures of different hydrometeor types in terms of the same radiometric channels that are used by the GMI. To mimic this, they used high-resolution data from passive microwave airborne instruments gathered during the Midlatitude Continental Convective
Cloud Experiment (MC3E) campaign. The corresponding hydrometeor-identification fields were produced from dual-polarimetric Weather Surveillance Radar-1988 Doppler radar data collected at Vance Air Force Base in Oklahoma. The results were probability distribution functions of the occurrence of 10 hydrometeor types.

The study whose results are presented here aims to evaluate the capability of GPM observations to detect hail by utilizing both passive and active measurements of the Core Observatory satellite. We emphasize that the results presented here are resolution dependent and may change with the development of the aerospace industry. For the resolution of the GMI observables, see Table 1 . In contrast to previous studies (e.g., Cecil 2009, 2011; Ferraro et al. 2015; Kitzmiller et al. 1995), we are interested in detection of hail shafts not only at the ground but also aloft, which is of great importance for improving the accuracy of convective precipitation retrievals (Grecu et al. 2016). The addition of hail and high-density graupel in forward-model simulations should help to reproduce the true microphysical state of the convective system with a more precise estimate of ice-phase water content. This is critical for quantifying the multiplescattering enhancement in the dual-frequency precipitation radar (DPR) measurements in convective storms. Multiple scattering occurs when the radar pulse energy is scattered several times off atmospheric targets before returning to the receiver [for details, see Battaglia et al. (2014)]. This phenomenon results in anomalous behavior of the reflectivity profiles below the freezing level. It mainly has an impact on Ka band, but in the most extreme cases $\mathrm{Ku}$ channel is also affected (Battaglia et al. 2016).

The hail-detection capabilities of the GPM satellite are tested, over the continental United States, with already established proxies like the height of the 40-dBZ radar reflectivity-level or TB depressions. In addition, new parameters like the mean mixed-phase reflectivity or the integrated reflectivity are considered. The examination is carried out with radiometric and radar measurements analyzed separately or combined to check which instrument or which pair of observations provides the most accurate information on hail presence. Following the method of Leppert and Cecil (2015), hydrometeor classification from polarimetric radar observations is used, rather than ground hail reports, as the validation data. This choice is motivated by the type of observations used in our case. The GPM satellite is on a low Earth orbit, and therefore its measurements are only snapshots of precipitating systems (the mean revisit time of the Ku radar in the continental United States varies from 3.5 to 5.2 days depending on the latitude). 
TABLE 1. GMI channels and their orbital configuration. Polarization codes: V is vertical and $\mathrm{H}$ is horizontal.

\begin{tabular}{cccccc}
\hline \hline Center frequency $(\mathrm{GHz})$ & Polarization & Nadir angle $\left(^{\circ}\right)$ & Earth incidence angle $\left(^{\circ}\right)$ & Beamwidth $\left({ }^{\circ}\right)$ & Footprint $(\mathrm{km} \times \mathrm{km})$ \\
\hline 10.65 & $\mathrm{~V} / \mathrm{H}$ & 48.5 & 52.821 & 1.72 & $32.1 \times 19.4$ \\
18.7 & $\mathrm{~V} / \mathrm{H}$ & 48.5 & 52.821 & 0.98 & $18.1 \times 10.9$ \\
23.8 & $\mathrm{~V}$ & 48.5 & 52.821 & 0.85 & $16.0 \times 9.7$ \\
36.64 & $\mathrm{~V} / \mathrm{H}$ & 48.5 & 52.821 & 0.81 & $15.6 \times 9.4$ \\
89 & $\mathrm{~V} / \mathrm{H}$ & 48.5 & 52.821 & 0.38 & $7.2 \times 4.4$ \\
166 & $\mathrm{~V} / \mathrm{H}$ & 45.36 & 49.195 & 0.37 & $6.3 \times 4.1$ \\
$183.31 \pm 3$ & $\mathrm{~V}$ & 45.36 & 49.195 & 0.37 & $5.8 \times 3.8$ \\
$183.31 \pm 7$ & $\mathrm{~V}$ & 45.36 & 49.195 & 0.37 & $5.8 \times 3.8$ \\
\hline
\end{tabular}

In the case of quickly evolving convective towers, it is a challenging task to associate the hail report with the stage of the observed precipitating system. In addition, the number of hail reports is strongly related to the population of a region, with rural areas typically being underrepresented (Doswell et al. 2005). Moreover, hail observed by a radar can melt before hitting the ground, depending on the lowlevel temperature and relative humidity.

\section{Data}

Collocated data from the NEXRAD network and the GPM Core Observatory satellite for the period spanning April 2014-June 2016 are utilized for this study. NEXRAD is a network of 160 high-resolution S-band Doppler dual-polarimetric weather radars operating in the United States. From all precipitating events captured by the GPM satellite over the continental United States, only those producing $\mathrm{Ku}$ reflectivity values of at least $40 \mathrm{dBZ}$ (not corrected for attenuation) above the freezing level are considered. In addition, the precipitation events are carefully selected to ensure that they are not farther than $150 \mathrm{~km}$ from the nearest S-band radar, where the vertical resolution of ground-based measurements is relatively coarse (up to $2.3 \mathrm{~km}$ ). Although at these ranges the beam size is too big to trust details of the vertical structure of the storm, such a range was selected to maximize the sample size. In this manner, 311 intense and extensive storms simultaneously observed by NEXRAD and GPM were selected (see Fig. 1), which means that some isolated/small convective systems might be omitted in our analysis because of the coarse resolution of the DPR or NEXRAD measurements beyond $100 \mathrm{~km}$. Because the ground-based radars sample the atmosphere in three dimensions, the full volume scan closest in time to the GPM overpass was analyzed for each weather event.

Because of its $65^{\circ}$-inclination orbit, the GPM satellite provides observations in the tropics and in the midlatitudes. For an overview of science goals and technical specifications, see Hou et al. (2014). The Core Observatory is equipped with the dual-frequency precipitation radar, operating at $\mathrm{Ku}(13.6 \mathrm{GHz})$ and $\mathrm{Ka}(35.5 \mathrm{GHz})$ bands, with swath widths of approximately 245 and $120 \mathrm{~km}$, respectively. In the inner overlapping swath, measurements are performed synchronously, and because both radars have the same antenna beamwidth of $0.71^{\circ}$ (the footprint diameter of $\sim 5 \mathrm{~km}$ ) they provide collocated radar reflectivity factor profiles. Our dataset of intense storms consists of approximately $0.72 \times 10^{6}$ and $0.4 \times 10^{6} \mathrm{Ku}$ and Ka vertical profiles, respectively. For this study, measured reflectivities that are not corrected for attenuation are used. In conditions of extreme weather, the attenuation correction is prone to errors, especially when high-density ice particles are present in the DPR field of view and extreme values of path-integrated attenuation are observed. Therefore, we prefer to look for metrics that are not dependent on the quality of the attenuation-correction process. In addition, when dualfrequency data are considered, the differential attenuation might be used as a source of additional information.

To visualize the DPR capability, we present horizontal cuts through the reflectivity data gathered on 5 June 2014, when the GPM satellite was passing over a

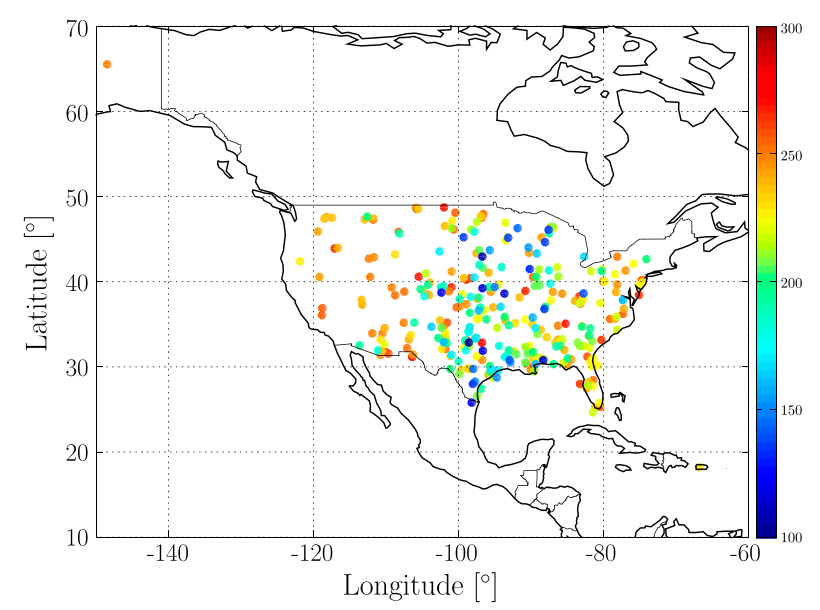

FIG. 1. The locations of 311 intense storms simultaneously observed by the GPM Core Observatory satellite and the NEXRAD network. The marker color corresponds to the lowest TB (K) at 36.6 GHz that was observed within the storm extent. 
(a)

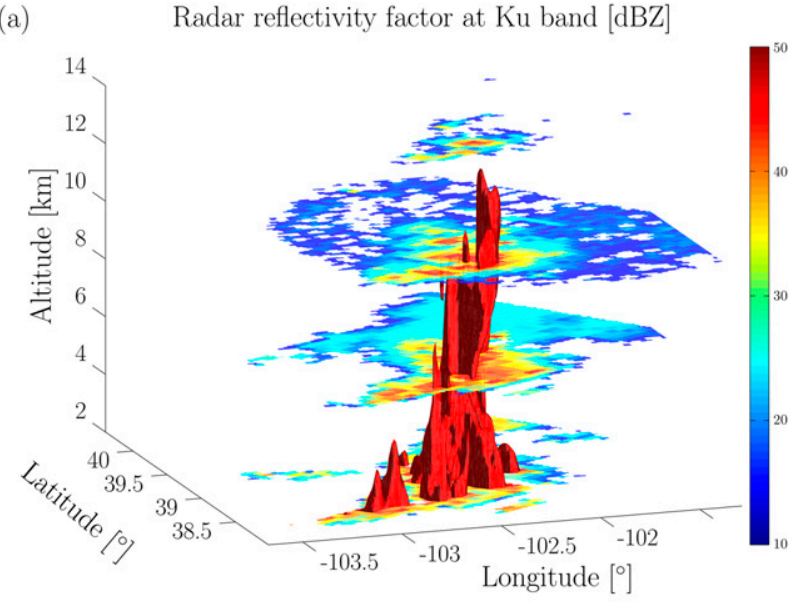

(c)

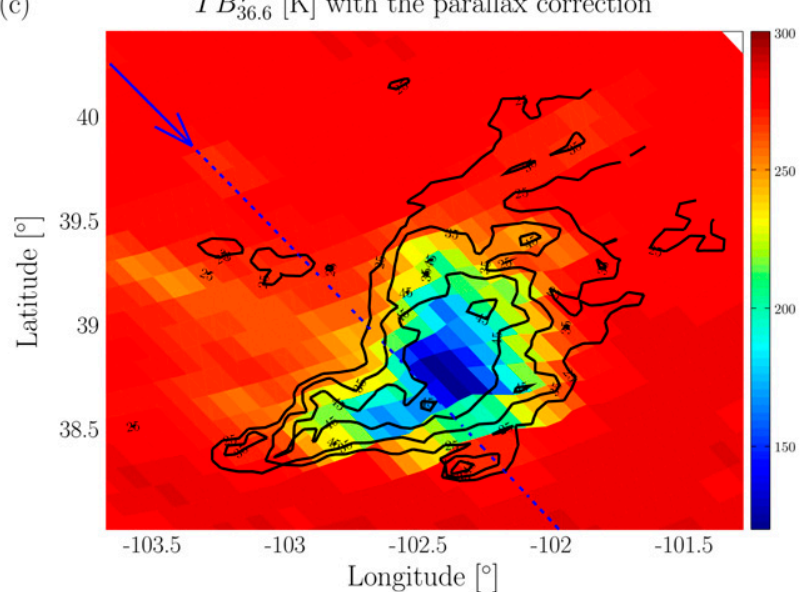

(b)

b) Radar reflectivity factor at Ka band [dBZ]

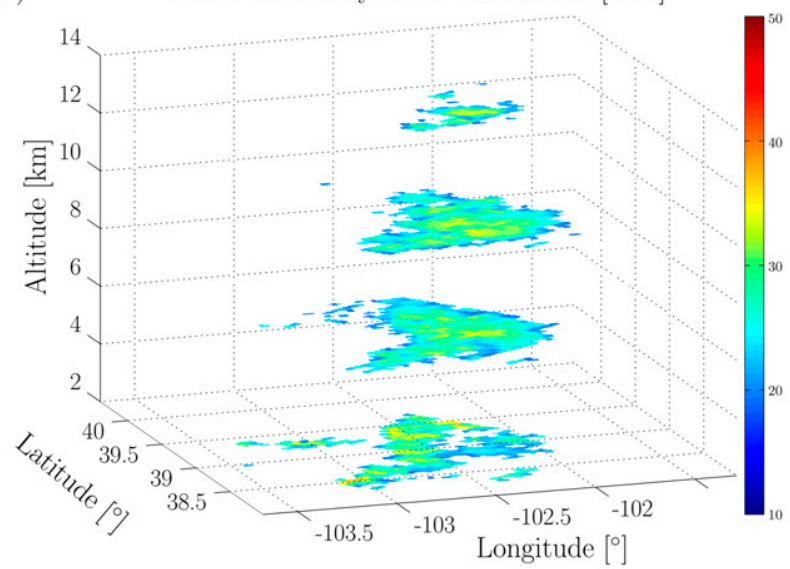

(d)

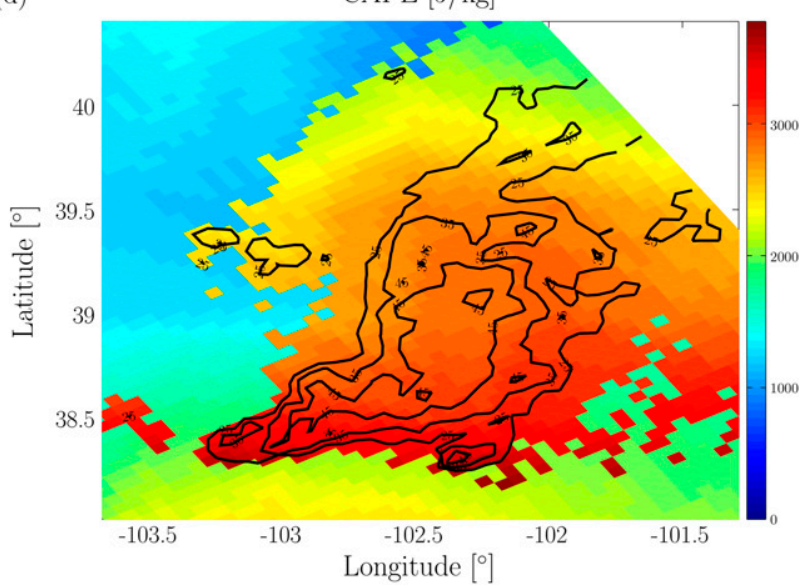

FIG. 2. GPM measurements of the thunderstorm that occurred on 5 Jun 2014, on the border between Kansas and Colorado: the radar reflectivity factor at (a) Ku and (b) Ka band at 2, 6, 10, and $14 \mathrm{~km}$ above sea level (the red surface corresponds to the 45-dBZ radar echo), (c) the vertical-polarization TB at $36.6 \mathrm{GHz}$ after the parallax correction based on Ku reflectivity measurements (the contour lines of 25 , 35 , and $45 \mathrm{dBZ}$ show the maximum reflectivity values in the vertical column that have been observed at Ku band), and (d) CAPE based on atmospheric state information from the 2 ADPRENV product.

thunderstorm that developed on the border between Colorado and Kansas (see Figs. 2a,b). The Ku observations clearly detail the storm structure. The dark-red surface indicates the $45-\mathrm{dB} Z$ values of radar reflectivity that highlight the core of the system, that is, the region of intense rainfall, or where a large amount of dense ice particles is expected. The Ka data also indicate the region of highly reflective particles above the $0^{\circ} \mathrm{C}$ isotherm, but below the freezing level strong attenuation masks the Ka signal. The analysis of atmospheric state information from the GPM level-2A DPR environment (2ADPRENV) product shows that the storm was characterized by very strong instability. The convective available potential energy (CAPE) exceeded exceptionally high values (Brooks et al. 2003) of $3 \mathrm{~kJ} \mathrm{~kg}^{-1}$ within the storm core; in some places they reached $3.7 \mathrm{~kJ} \mathrm{~kg}^{-1}$ !
The radiometer aboard the GPM satellite operates at 13 different channels ranging from 10.6 to $183 \mathrm{GHz}$, with corresponding beamwidths from $1.72^{\circ}$ to $0.37^{\circ}$ (Hou et al. 2014). Although there are known deconvolution techniques (Stogryn 1978), no attempt to account for the different footprint sizes is made here. To exclude possible contributions to the overall uncertainty introduced by the deconvolution process, we opted to analyze the measurements at their native resolution. The slanted geometry of GMI scans introduces the parallax-effect problem, which is a major issue when dealing with tall convective systems. For example, when 15-km-high, optically thick systems are observed at a $50^{\circ}$ viewing angle, there is an $\sim 17-\mathrm{km}$ horizontal mismatch between the sampled volume and the point at which the boresight intersects the Earth ellipsoid. The parallax adjustment adopted here is based on a proxy built from the $\mathrm{Ku}$ 
reflectivity measurements. The latitude and longitude coordinates of scans at frequencies of greater than or equal to $89 \mathrm{GHz}$ are redefined as those corresponding to the highest point of intersection between the GMI boresight and the isosurface of the $\mathrm{Ku}$ reflectivities equal to $25 \mathrm{dBZ}$. For lower-frequency TBs, stronger reflectivity echoes are used; that is, for the $36.6-\mathrm{GHz}$ channel, we use the 35-dBZ level, whereas for 10.6, 18.7, and $23.8 \mathrm{GHz}$, the $45-\mathrm{dBZ}$ level is used. The result of this procedure is illustrated in Fig. 2c, in which a contour of the maximum $\mathrm{Ku}$ reflectivity indicates the real position of the precipitating system. This correction greatly improves the correlation between the TB depressions and the peak of the observed maximum reflectivity. After applying the parallax correction, we linearly interpolate measured TBs onto the DPR grid.

Electromagnetic radiation emerging from water surfaces is partially polarized, with horizontally polarized radiation being characterized by lower emissivities. The degree of polarization depends on the frequency of the signal and on the viewing angle, with the lower-frequency channels being affected the most. To avoid confusion between water surfaces (lake and oceans) and storms, the polarization-corrected temperature (PCT) is used at 89- and 36.6-GHz channels (Spencer et al. 1989; Cecil et al. 2002):

$$
\begin{aligned}
& \mathrm{TB}_{36.6}^{\mathrm{PC}}=2.2 \mathrm{~TB}_{36.6}^{\mathrm{V}}-1.2 \mathrm{~TB}_{36.6}^{\mathrm{H}} \text { and } \\
& \mathrm{TB}_{89}^{\mathrm{PC}}=1.818 \mathrm{~TB}_{89}^{\mathrm{V}}-0.818 \mathrm{~TB}_{89}^{\mathrm{H}} .
\end{aligned}
$$

In storms, there is almost no difference between vertically $(\mathrm{V})$ and horizontally $(\mathrm{H})$ polarized radiation, and polarization-corrected TBs are nearly equal to the observed TBs. There is unfortunately no formula for the PCT at lower and higher frequencies, and therefore both polarization channels are used.

\section{Method}

Data used in our analysis come from two different sources; therefore, they must be resampled to the same grid before any comparison is made. Also, the space of considered observables and the verification measures that are involved in the examination process must be defined. All of these steps are briefly summarized in sections $3 \mathrm{a}-3 \mathrm{c}$.

\section{a. Ground-based radar data preparation}

NEXRAD data are first subjected to quality control according to the procedure described by Lang et al. (2007) and modified using the open-source analysis framework enabled by Helmus and Collis (2016). The quality-controlled NEXRAD data are converted from spherical coordinates to the Cartesian gridding using an azimuthal-equidistant projection with $1-\mathrm{km}$ vertical and horizontal resolution. The gridding is performed using a Barnes weighting function with a radius of influence that increases with range from the radar. The minimum value for the radius of influence is $500 \mathrm{~m}$.

Fuzzy-logic hydrometeor classification (HID), based on S-band modifications to Dolan and Rutledge (2009) and Dolan et al. (2013), is applied to the gridded data. This HID uses four radar observables (horizontalpolarization reflectivity, differential reflectivity, specific differential phase, and correlation coefficient) along with temperature to distinguish 10 hydrometeor types: big drops (BD), hail (HL), high-density graupel (HG), low-density graupel (LG), vertically oriented ice (VI), wet snow (WS), aggregates (AG), ice crystals (CR), rain $(\mathrm{RN})$, and drizzle (DZ). A size distinction between hail and graupel is given by a diameter of $5 \mathrm{~mm}$; for the other size and density ranges we refer readers to Dolan and Rutledge (2009) and Dolan et al. (2013). An example of the three-dimensional (3D) hydrometeor-classification field is shown in Fig. 3b.

To simplify the analysis, the 3D structure of precipitating species is projected vertically onto the Earth surface using a hierarchy of hydrometeor categories. Such a dimensional reduction is necessary if we want to use two-dimensional (2D) TB data in our analysis.

For each hydrometeor type a certain priority is assigned, and then the hydrometeor with the highest priority in the vertical profile is attributed to each column. The priority of hydrometeor types in descending order is as follows: HL, HG, LG, AG, CR combined with VI, and a final group that combines all liquid-phase hydrometeors and WS. All liquid-phase hydrometeors have the lowest priority because we are mainly interested in high-density ice particles. Moreover, in the case of strong convection, most of the radiation sensed by the radiometer comes from hydrometeors above the freezing level, and only low-frequency channels (18.7 and $10.6 \mathrm{GHz}$ ) are sensitive to the liquid-phase species that are present below the $0^{\circ}$ isotherm (Mugnai et al. 1993). The hierarchy of the solid-phase species roughly reflects their backscattering properties; for example, one expects stronger reflectivity echoes from hail than from graupel, and so on.

In this manner, a 2D field is produced in which hail is assigned to the column if present anywhere in it, regardless of the presence of other species. Profiles with rain are those for which liquid-phase hydrometeors are the only ones occurring in the column. The 2D mapping that corresponds to the $3 \mathrm{D}$ structure from Fig. $3 \mathrm{~b}$ is shown in Fig. 3c. 
(a)

(a)

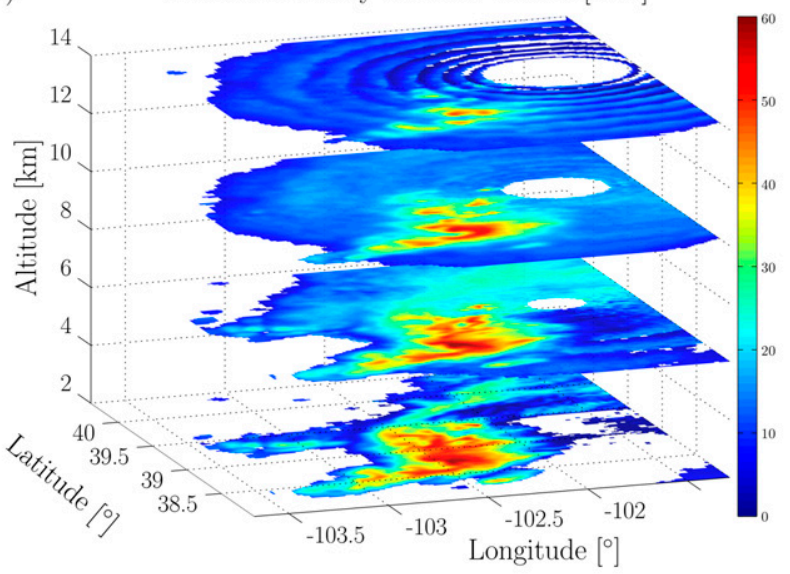

(c)

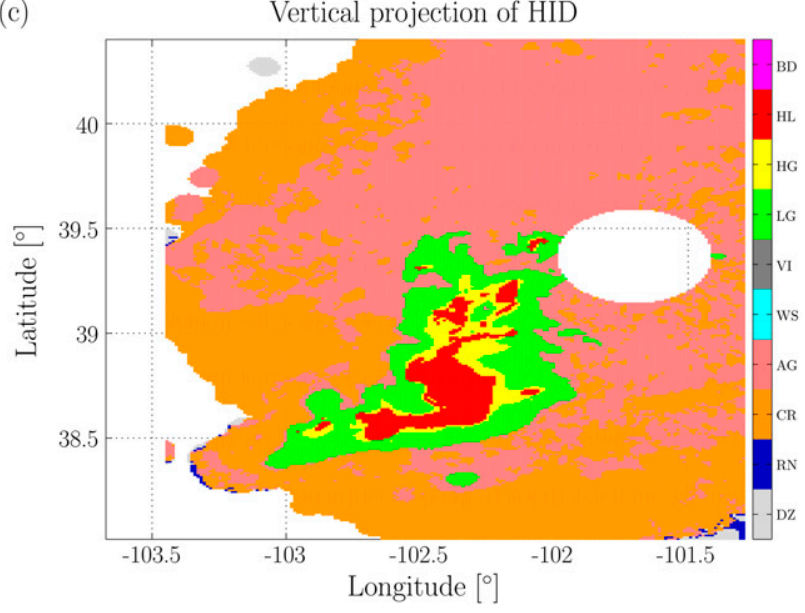

(b)

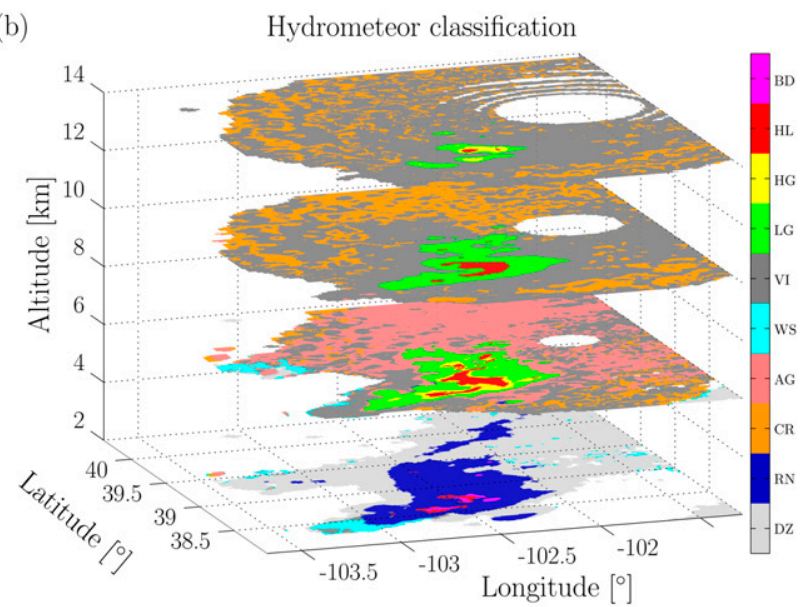

(d)

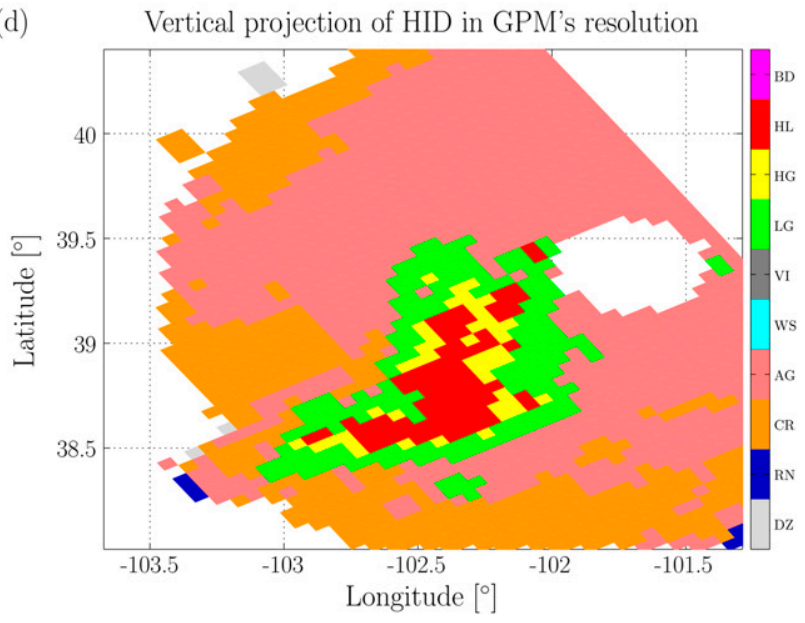

FIG. 3. Ground-based observations of the storm from Fig. 2 and the corresponding hydrometeor classification, as depicted by horizontal slices at altitudes of 2, 6, 10, and $14 \mathrm{~km}$ through the 3D structure of (a) the radar reflectivity factor measured from the nearest NEXRAD station, (b) HID based on polarimetric observables, (c) 2D hierarchical mapping of HID, and (d) 2D projection averaged to the DPR field of view.

Once a $2 \mathrm{D}$ map is produced at the resolution of the S-band Cartesian dataset used in this study $\left(1 \times 1 \mathrm{~km}^{2}\right)$, it is resampled at the GPM DPR footprint $\left(20 \mathrm{~km}^{2}\right)$. Therefore, a Gaussian approximation of the two-way antenna gain specific for the DPR configuration,

$$
G^{2}(r)=\left(\frac{8 \ln 2}{d_{\mathrm{DPR}}^{2} \pi}\right) \exp \left(-\frac{8 r^{2} \ln 2}{d_{\mathrm{DPR}}^{2}}\right),
$$

is used to calculate the fraction of a footprint that is occupied by each hydrometeor type; $r$ denotes the range in kilometers to the point at which the DPR boresight intersects the Earth ellipsoid and $d_{\mathrm{DPR}}(=5.04 \mathrm{~km})$ is a diameter of the DPR footprint. The dominant precipitation type is the one with the highest priority that fills in at least $10 \%$ of the DPR field of view $\left(\sim 2 \mathrm{~km}^{2}\right)$. This area is large enough for hailstones to produce observable enhancements in the radar reflectivity and the TB depressions.
Figure $3 \mathrm{~d}$ shows how the averaging procedure changes the high-resolution hydrometeor-classification data into a field with the DPR footprint size.

\section{b. Spaceborne observables}

To compare the hail-occurrence map with the DPR observables, several parameters that describe bulk properties of each reflectivity profile are studied. We employ proxies such as the highest altitude above the freezing level of the 40-, 35-, 30-, 25-, and 20-dBZ Ku reflectivity isosurface that were well established during the TRMM era (Zipser et al. 2006; Nesbitt et al. 2000; Liu et al. 2008). These parameters are physically related to the vigor of convection: the stronger the updraft is, the bigger are the particles high up in the troposphere. We emphasize that all reflectivity-level heights are relative to the $0^{\circ} \mathrm{C}$ isotherm coming from the GPM 2ADPRENV product—for example, 


$$
\mathrm{H} 40^{\mathrm{AFL}}=\mathrm{H} 40^{\mathrm{ASL}}-\mathrm{FLH},
$$

where the superscripts AFL and ASL stand for above the freezing level and above sea level and FLH is the altitude of the freezing level. To define a metric that is not regional, the positions of reflectivity levels relative to the tropopause and the freezing level are also considered-for example,

$$
\mathrm{H} 40^{n}=\frac{\mathrm{H} 40^{\mathrm{AFL}}}{\mathrm{TH}-\mathrm{FLH}},
$$

where TH is the tropopause height.

In addition, we use the maximum reflectivity value in the column and the integrated reflectivity defined as the integral (in logarithmic units) of the measured reflectivity ( $Z$ in linear units) from the cloud top to the freezing level:

$$
Z^{\text {int }}=10 \log _{10} \int_{\mathrm{FLH}}^{\mathrm{CTH}} Z(h) d h,
$$

where CTH stands for the cloud-top height and $h$ is the height in meters. The CTH is determined by the top altitude of eight contiguous radar range gates where the $\mathrm{Ku}$ reflectivity is greater than the minimal detectable value of $12 \mathrm{dBZ}$. By doing this, we are able to screen out most of the instrument noise that could be interpreted as high-level clouds. We use measurements only above the $0^{\circ}$ isotherm because we are mainly interested in solid-phase hydrometeor classification. Notice that $Z_{\text {int }}$ is measured in $10 \log _{10}\left(\mathrm{~mm}^{6} \mathrm{~m}^{-2}\right)$; for simplicity, we denote this unit as $\mathrm{dB} Z_{\text {int }}$. The mixedphase reflectivity is also considered. It is defined as the average (in logarithmic units) over the 4-km layer of measured reflectivity (in linear units) above the $-10^{\circ} \mathrm{C}$ isotherm:

$$
Z^{\mathrm{mix}}=10 \log _{10}\left[\int_{-10^{\circ} \mathrm{C}}^{-10^{\circ} \mathrm{C}+4 \mathrm{~km}} Z(h) d h / 4 \mathrm{~km}\right]
$$

Although supercooled water is not always present above the freezing level, the region used for averaging roughly corresponds to the temperature ranges where mixedphase water can be found, assuming a typical lapse rate of $6.5 \mathrm{~K} \mathrm{~km}^{-1}$.

To use the full potential of the GPM satellite, the 20-, 25-, 30-, and 35-dBZ Ka reflectivity-level heights and the integrated mean maximum reflectivity at Ka band are also tested. Although Ka signal is strongly attenuated by scattering and cloud liquid water well above the freezing level, we use the same reflectivity-level heights for defining the integrated and mixed-phase reflectivities that we used for $\mathrm{Ku}$ band.
In addition, the maximum dual-wavelength ratio (DWR) and the highest 10-dB DWR-level altitudes are introduced. Notice that the DWR is driven by three factors: Mie scattering, attenuation effect, and multiple scattering. For instance, a $10-\mathrm{dB}$ difference between $\mathrm{Ku}$ and $\mathrm{Ka}$ reflectivity factors can be produced by hailstones of $20 \mathrm{~mm}$ in diameter (difference in scattering properties) or when the Ka-band signal is attenuated by a $5-\mathrm{km}$ layer of $1 \mathrm{~g} \mathrm{~m}^{-3}$ of small graupel ( $\sim 2 \mathrm{~mm}$ in diameter).

A full list and a description of parameters considered in our analysis can be found in Table 2. Each of these parameters is qualitatively related to general aspects of a hail storm, but none of them can be construed as a direct measure or detector of hail in all of its forms and structures. Our analysis aims to assess which of these observables presents the best correlation with a hailoccurrence map.

Once the hydrometeor-classification field in the DPR resolution is produced, the sensitivity of the GPM parameters to the presence of specific hydrometeor types, with focus on hail, is assessed. If only one individual parameter is considered, the only available approach is to define a threshold that determines the hail-occurrence likelihood. In this way, the threshold value on each parameter defines a hail-detection algorithm (HDA). An example of such an approach can be found in Cecil (2009), where the thresholding value of $180 \mathrm{~K}$ on polarization-corrected $\mathrm{TB}$ at $36.6 \mathrm{GHz}$ was proposed.

\section{c. Verification measures}

To quantify the accuracy and the skill of a particular algorithm, we consider the probability of detection (POD), the false-alarm rate (FAR), and the threat score or critical success index (CSI), defined as in Schaefer (1990),

$\mathrm{POD}=\frac{h}{h+m}, \quad \mathrm{FAR}=\frac{f}{h+f}, \quad$ and $\quad \mathrm{CSI}=\frac{h}{h+m+f}$

Here, $h, f$, and $m$ stand for the number of hits, false alarms, and missed detections, respectively.

Figure $4 \mathrm{~b}$ shows the likelihood of occurrence of certain hydrometeor types depending on the $40-\mathrm{dBZ} \mathrm{Ku}$ reflectivity-level height. The probability functions indicate that LG is expected when the $40-\mathrm{dB} Z$ echo reaches only up to $0.8 \mathrm{~km}$ AFL (i.e., $\mathrm{H} 40_{\mathrm{Ku}}^{\mathrm{AFL}}<0.8$ ), $\mathrm{HG}$ is likely when the same echo is observed up to $4.2 \mathrm{~km} \mathrm{AFL,}$ and $\mathrm{HL}$ occurrence is associated with $\mathrm{H} 40_{\mathrm{Ku}}^{\mathrm{AFL}}>4.2 \mathrm{~km}$. At the same time, the maximum value of the CSI is obtained for $\mathrm{H} 40_{\mathrm{Ku}}^{\mathrm{AFL}}=3.26 \mathrm{~km}$ (Fig. 4a), which corresponds to a FAR of $49.4 \%$ and a POD of $70.5 \%$. Had 
TABLE 2. GPM observables tested as proxies for hail detection.

\begin{tabular}{|c|c|c|}
\hline Notation & Description & Units \\
\hline $\mathrm{H} 20_{\mathrm{Ku}(\mathrm{Ka})}^{\mathrm{AFL}} ; \mathrm{H} 25_{\mathrm{Ku}(\mathrm{Ka})}^{\mathrm{AFL}} ; \mathrm{H} 30_{\mathrm{Ku}(\mathrm{Ka})}^{\mathrm{AFL}} ; \mathrm{H} 35_{\mathrm{Ku}(\mathrm{Ka})}^{\mathrm{AFL}} ; \mathrm{H} 40_{\mathrm{Ku}(\mathrm{Ka})}^{\mathrm{AFL}}$ & $\begin{array}{l}\text { 20-, 25-, 30-, 35-, 40-dBZ Ku }(\mathrm{Ka}) \\
\quad \text { reflectivity-level height above the } 0^{\circ} \text { isotherm }\end{array}$ & $\mathrm{km}$ \\
\hline $\mathrm{H} 40_{\mathrm{Ku}}^{n} ; \mathrm{H} 30_{\mathrm{Ka}}^{n}$ & $\begin{array}{l}\text { 40-dBZ Ku and } 30-\mathrm{dB} Z \mathrm{Ka} \text { reflectivity-level heights } \\
\text { above the freezing level normalized by the } \\
\text { tropopause altitude }\end{array}$ & - \\
\hline$Z_{\mathrm{Ku}(\mathrm{Ka})}^{\max }$ & Max reflectivity in the column & $\mathrm{dBZ}$ \\
\hline$Z_{\mathrm{Ku}(\mathrm{Ka})}^{\mathrm{Ku} \text { (Na) }}$ & Column-integrated reflectivity & $\mathrm{dB} Z_{\text {int }}$ \\
\hline$Z_{\mathrm{Ku}(\mathrm{Ka})}^{\min }$ & Mean reflectivity in the mixed-phase layer & $\mathrm{dB} Z$ \\
\hline$H_{10 \mathrm{~dB}}^{\mathrm{AFL}} ; H_{10 \mathrm{~dB}}^{n}$ & $\begin{array}{l}\text { 10-dB differential reflectivity-level height above the } \\
\text { freezing level, not normalized and normalized by the } \\
\text { tropopause altitude }\end{array}$ & $\mathrm{km},-$ \\
\hline $\mathrm{TB}_{10.6}^{\mathrm{V}(\mathrm{H})} ; \mathrm{TB}_{18.7}^{\mathrm{V}(\mathrm{H})} ; \mathrm{TB}_{23.8}^{\mathrm{V}} ; \mathrm{TB}_{36.6}^{\mathrm{PC}} ; \mathrm{TB}_{89}^{\mathrm{PC}} ; \mathrm{TB}_{166}^{\mathrm{V}(\mathrm{H})} ; \mathrm{TB}_{183.3 \pm 3}^{\mathrm{V}} ; \mathrm{TB}_{183.3 \pm 7}^{\mathrm{V}}$ & TBs at different frequencies and polarizations & $\mathrm{K}$ \\
\hline
\end{tabular}

this threshold changed to $4.2 \mathrm{~km}$, where the HL presence is most likely, the FAR and the POD would decrease to $39.9 \%$ and $54.9 \%$, respectively. The point at which the CSI reaches its maximum value does not correspond to the edge of a domain where HL is the most probable hydrometeor type; rather, it indicates where a compromise between FAR and POD is optimized according to the formulation above. It will be used as the optimum thresholding value for hail identification.

\section{Results}

The performance of the HDAs corresponding to all analyzed parameters is assessed with the CSI as a verification measure. In addition, the probability distribution functions (PDFs) of the occurrence of HL, HG, LG, $\mathrm{AG}$, and $\mathrm{CR}$ with respect to the best-performing observables are presented in Figs. 4b-f. The vertical black dashed line marks the threshold value associated with the maximum CSI. The efficiency of the best-performing parameters is summarized in Table 3, and the key finding are presented with distinction to different instruments in sections $4 a-4 c$.

\section{a. Radar-based proxies}

Three Ku-based parameters, $\mathrm{H} 40_{\mathrm{Ku}}^{\mathrm{AFL}}, Z_{\mathrm{Ku}}^{\mathrm{int}}$, and $Z_{\mathrm{Ku}}^{\mathrm{mix}}$, have very high CSI of $42 \%-45 \%$. All of them have similar FAR and POD, oscillating around $41 \%-49 \%$ and $65 \%-70 \%$, respectively.

The mixed-phase reflectivity $Z_{\mathrm{Ku}}^{\mathrm{mix}}$ provides information about the reflectivity in the mixed-phase layer where hail forms. It is expected that higher values of $Z_{\mathrm{Ku}}^{\mathrm{mix}}$ are associated with events of more extreme weather; therefore, the probability of hail presence grows with increasing $Z_{\mathrm{Ku}}^{\mathrm{mix}}$ (see Fig. 4c). A similar variable was already considered by Cecil (2011) as a parameter related to hail. He used the following massreflectivity $(M-Z)$ relation:

$$
M=0.00344 Z^{4 / 7},
$$

to convert the reflectivity $Z\left(\mathrm{~mm}^{6} \mathrm{~m}^{-3}\right)$ into the ice mixing ratio $M\left(\mathrm{~g} \mathrm{~m}^{-3}\right)$, and then the resulting ice water content (IWC) was averaged over a 4-km-deep layer beginning at $-10^{\circ} \mathrm{C}$. The calculation of $Z_{\mathrm{Ku}}^{\mathrm{mix}}$ is analogous, but the $M-Z$ conversion is avoided because we aim to relate radar observables, and not microphysical parameters, with hail occurrence. Since the mean mixedphase IWC was used in Cecil (2011) as a scaling factor for mapping the TBs from global ones toward values that would be observed in the United States, the mixedphase reflectivity is suitable for global hail detection.

As discussed in the previous section, the threshold value of $3.26 \mathrm{~km}$ AFL on $\mathrm{H} 40_{\mathrm{Ku}}^{\mathrm{AFL}}$ achieves a CSI of $42 \%$. Extreme reflectivity values high in the atmosphere were considered long before the GPM mission (Waldvogel et al. 1979) as a satisfactory criterion for hail detection. Zipser et al. (2006) suggested that the 40-dBZ height loosely correlates with the updraft speed in the midtroposphere, and our analysis shows that this proxy also correlates with the hail occurrence. This observable is strongly dependent on the tropopause height, however, with values expected to be bigger in the tropics for the same storm intensity. Therefore, the normalized version of this metric, $\mathrm{H} 40_{\mathrm{Ku}}^{n}$, was also analyzed. The $40-\mathrm{dBZ}$ reflectivity-level height scaled by the distance between the freezing level and the tropopause has a slightly lower CSI of $40 \%$. Although the troposphere height is not the only factor that drives the local climatological behavior, the normalization used here, at least in principle, may remove one of the contributors that make such a detection approach nonglobal.

The column-integrated reflectivity $Z_{\mathrm{Ku}}^{\mathrm{int}}$ is very similar to the vertically integrated liquid (VIL) proposed by Kitzmiller et al. (1995) as a severe-weather gauge, where reflectivity values in linear units were converted to the water content with an empirical relationship given by 
(a)

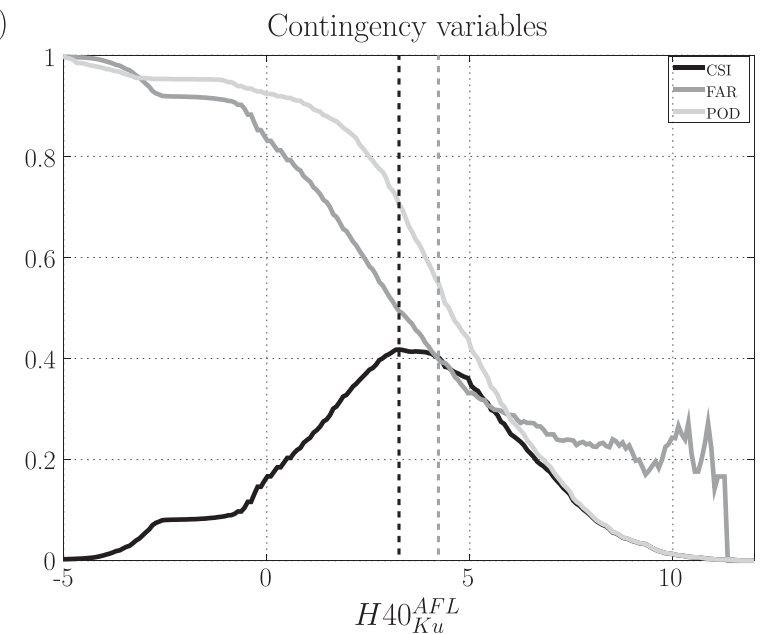

(c)

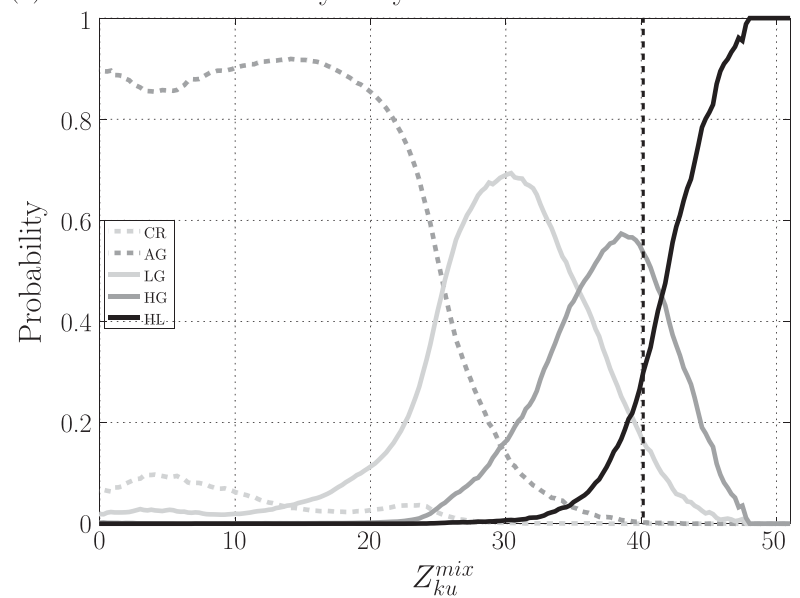

(e)

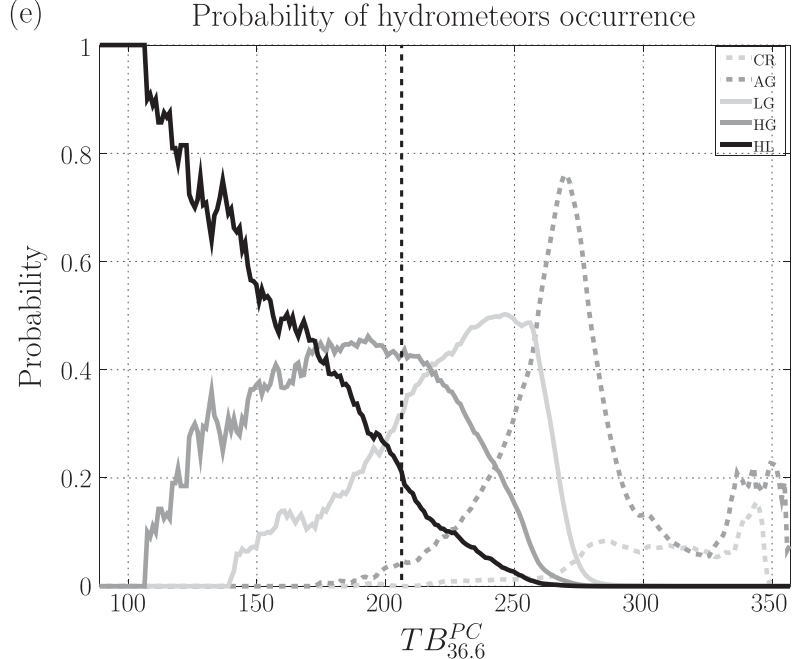

(b)

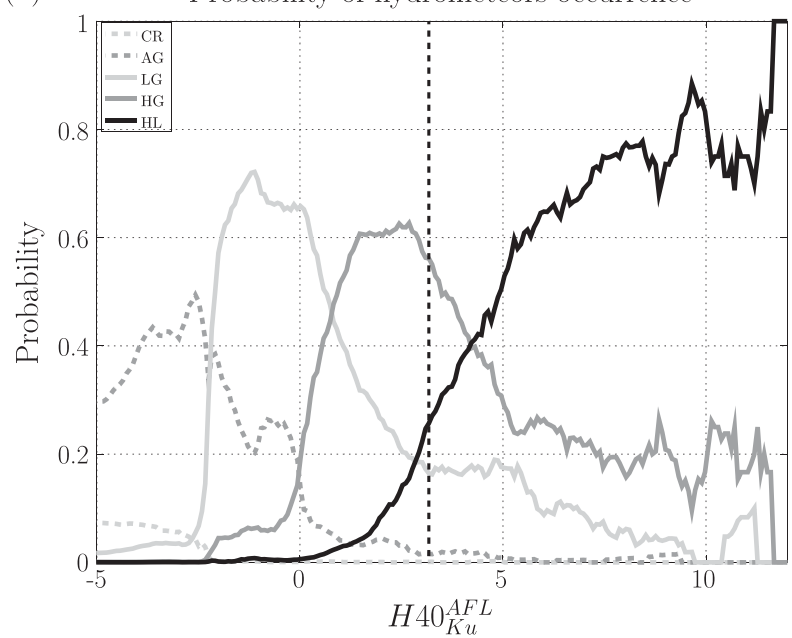

(d)

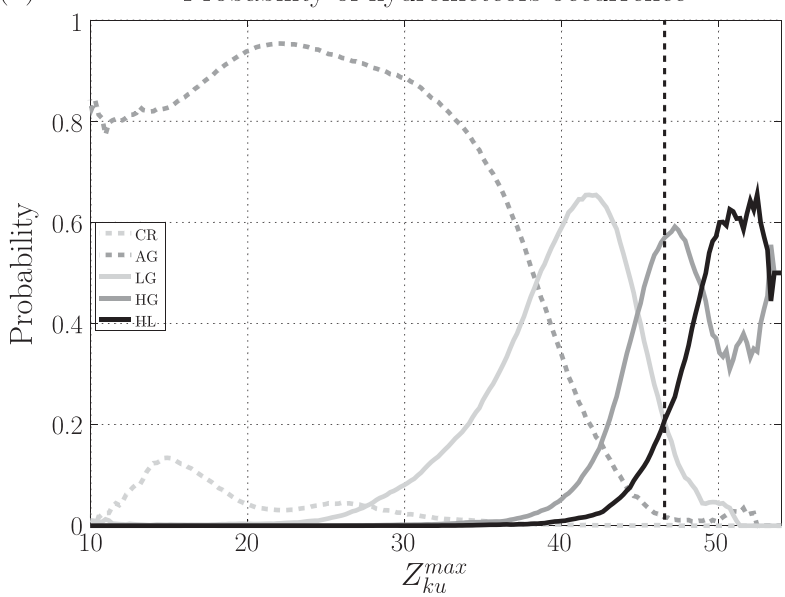

(f)

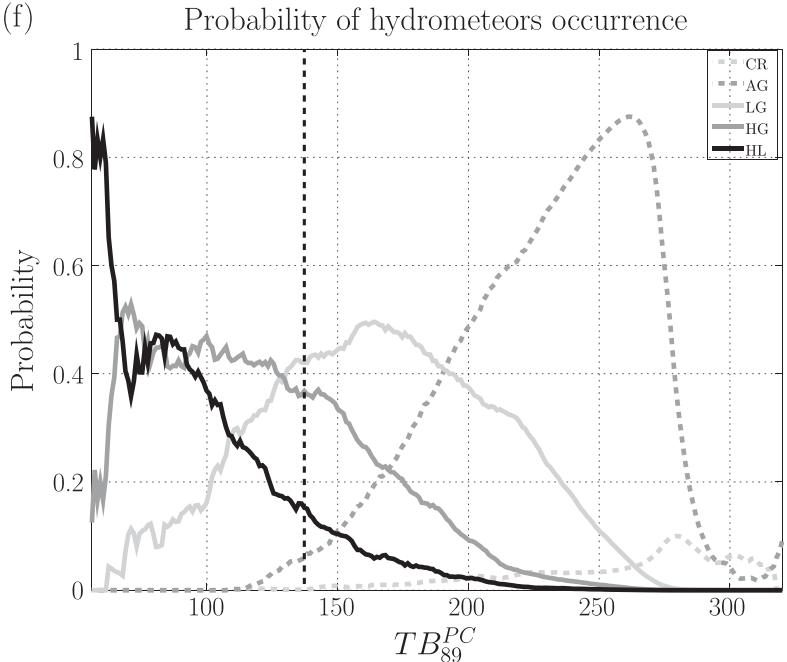

FIG. 4. (a) POD, FAR, and CSI for hail detection based on 40-dBZ Ku reflectivity-level height, and the probability of occurrence of solid-phase hydrometeor types depending on (b) $\mathrm{H}_{4} 0_{\mathrm{Ku}}^{\mathrm{AFL}}$, (c) $Z_{\mathrm{Ku}}^{\operatorname{mix}}$, (d) $Z_{\mathrm{Ku}}^{\max }$, (e) $\mathrm{TB}_{36.6}^{\mathrm{PC}}$, and (f) $\mathrm{TB}_{89}^{\mathrm{PC}}$. The vertical black and gray dashed lines mark the threshold value associated with the maximum CSI and the edge of a domain where hail is the most probable hydrometeor type, respectively. 
TABLE 3. Contingency parameters of the hail-detection algorithms based on the proxy value on the GPM observables.

\begin{tabular}{lccc}
\hline \multicolumn{1}{c}{ Condition } & CSI $(\%)$ & FAR $(\%)$ & POD $(\%)$ \\
\hline $\mathrm{TB}_{36.6}^{\mathrm{PC}}<207.27$ & 24.5 & 62.8 & 41.9 \\
$\mathrm{~TB}_{89}^{\mathrm{PC}}<138.30$ & 18.2 & 73.7 & 37.3 \\
$\mathrm{~TB}_{18.7}^{\mathrm{PC}}<260.63$ & 25.7 & 62.2 & 44.7 \\
$Z_{\mathrm{Ku}}^{\mathrm{mix}}>40.42$ & 44.9 & 41.0 & 65.3 \\
$Z_{\mathrm{Ku}}^{\mathrm{int}}>79.32$ & 43.4 & 43.3 & 64.8 \\
$Z_{\mathrm{Ku}}^{\max }>46.79$ & 25.2 & 64.1 & 45.8 \\
$\mathrm{H} 40_{\mathrm{Ku}}^{\mathrm{AFL}}>3.26$ & 41.8 & 49.4 & 70.5 \\
$\mathrm{H} 40_{\mathrm{Ku}}^{n}>0.27$ & 39.7 & 52.1 & 70.0 \\
$Z_{\mathrm{Ka}}^{\mathrm{mix}}>29.19$ & 22.7 & 73.7 & 62.1 \\
$Z_{\mathrm{Ka}}^{\mathrm{int}}>68.79$ & 27.2 & 62.0 & 48.7 \\
$Z_{\mathrm{Ka}}^{\max }>33.95$ & 11.5 & 81.6 & 23.3 \\
$\mathrm{H} 30_{\mathrm{Ka}}^{\mathrm{AFL}}>5.23$ & 29.8 & 61.5 & 56.7 \\
$\mathrm{DWR}{ }_{\max }>21.77$ & 18.1 & 78.7 & 55.2 \\
$H_{10 \mathrm{~dB}}^{\mathrm{AFL}}>4.50$ & 20.8 & 74.1 & 51.5 \\
$H_{10 \mathrm{~dB}}^{n}>0.41$ & 20.2 & 72.5 & 43.4 \\
\hline
\end{tabular}

Eq. (10) and then integrated vertically. Again, the conversion process is omitted in our analysis, but, like exceptionally large total water mass in the column, high values of the integrated reflectivity are indicators of extreme weather.

The hail-detection algorithm based on the simple measure of storm strength $Z_{\mathrm{Ku}}^{\max }$ performs very poorly (CSI of $25 \%$ ). The probability distribution functions shown in Fig. $4 d$ indicate that $Z_{\mathrm{Ku}}^{\max }$ has no skills to discriminate between $\mathrm{HL}$ and $\mathrm{HG}$.

When $35-\mathrm{GHz}$ radar measurements are considered, the best-performing criteria for hail detection are based on $\mathrm{H} 30_{\mathrm{Ka}}^{\mathrm{AFL}}, \mathrm{H} 25_{\mathrm{Ka}}^{\mathrm{AFL}}$, and $Z_{\mathrm{Ka}}^{\text {int }}$, which are clearly mirroring Ku-band observables. Nevertheless, their performance is at least $10 \%$ worse in terms of the CSI. The mixed-phase reflectivity at Ka band is not correlated with hail occurrence, which suggests that at altitudes just above the freezing level the $35-\mathrm{GHz}$ radar reflectivities are already strongly affected by attenuation. The only Ka observables that perform better than radiometric measurements are the height of the 25- and 30-dBZ reflectivity levels. The hail-detection capabilities of the Ka radar are not improved even when the reflectivity values corrected for attenuation, as derived from the GPM level-II official product, are used (not shown).

The differential reflectivity parameters considered here perform worse than $\mathrm{Ku}$ - and Ka-only observables. The maximum DWR proxy has a very high rate of false alarms $(79 \%)$, which suggests that it is driven mainly by differential attenuation rather than differences in backscattering properties of particles. The $H_{10 \mathrm{~dB}}^{\mathrm{AFL}}$ performs slightly better, with a CSI of only $20.8 \%$. Again, the use of radar reflectivity values corrected for attenuation does not help. In fact, we observe a drop in the CSI from $18.1 \%$ to $5.4 \%$ for $\mathrm{DWR}_{\max }$ and from $20.8 \%$ to $17.4 \%$ for $H_{10 \mathrm{~dB}}^{\mathrm{AFL}}$. This strongly suggests that, for severe-weather conditions, there is a large degree of uncertainty in the attenuationcorrection procedure.

\section{b. Radiometer-based proxies}

The radiometer-based proxies perform worse than the $\mathrm{Ku}$-band measures, as expected from the columnarintegrated nature of radiometric measurements. In addition, active measurements of a precipitating system are not dependent on the underlying surface, which is not the case for radiometric observations. Despite these premises, the algorithms utilizing the TBs have their own merit, since the swath of the GMI aboard the GPM satellite is much wider than the swath of the DPR.

Our study confirms the findings of Cecil (2009) that 36.6- and $89-\mathrm{GHz}$ radiometric channels are the best hail indicators among all passive measurements available from the GPM. Despite the different method and dataset, our PDF of hail occurrence in Fig. 4e is similar to the one presented in Cecil and Blankenship (2012). For $\mathrm{TB}_{36.6}^{\mathrm{PC}}<180 \mathrm{~K}$, the probability of hail is higher than that of the other species; this restrictive threshold was used by Cecil (2009) as a proxy for hail detection, but our analysis based on the CSI suggests the use of a more relaxed condition: $\mathrm{TB}_{36.6}^{\mathrm{PC}}<207 \mathrm{~K}$. At $89 \mathrm{GHz}$, the probability of $\mathrm{HL}$ and $\mathrm{HG}$ oscillates around 0.5 even for very low temperatures, which was also shown in Cecil (2009, his Fig. 2).

Although the mean TB at the $166,183.3 \pm 3$, and $183.3 \pm 7$ channels associated with profiles containing hail is lower than for the air parcels for which hail is not present (see Table 4), the spread of TB values measured for graupel (standard deviation of $40 \mathrm{~K}$ ) is large enough to broadly overlap with the region where hail is expected. To explore this phenomenon in more detail, we ran an ensemble of radiometric simulations with simplistic hydrometeor profiles. We set the emissivity of a land surface to be 0.9 and its temperature to $30^{\circ} \mathrm{C}$. The same profile of the water content and the mean volume diameter of rain was used for all runs. The profile of the mean volume diameter $D_{m}$ was assumed to be a nonincreasing, piecewise linear function of the height, whereas the hydrometeor density was set to be constant. A wide range of possible density-diameter pairs was explored, and all profiles whose density was greater than $0.5 \mathrm{~g} \mathrm{~cm}^{-3}$ and $1<D_{m}<8 \mathrm{~mm}$ produced TBs below $100 \mathrm{~K}$ at $166 \mathrm{GHz}$. This result is consistent with our statistical findings that low TB values are associated not only with hail but with graupel also.

On the other side of the spectrum of GMI channels (i.e., for 10.6 and $18.7 \mathrm{GHz}$ ), the nonuniform beamfilling becomes a challenging problem because of the larger 
TABLE 4. The mean value of the TB associated with the solidphase hydrometeor types, derived from the GMI measurements of 311 intense storms simultaneously observed by the GPM satellite and the NEXRAD network.

\begin{tabular}{lccccc}
\hline \hline Channel & HL & HG & LG & AG & CR \\
\hline $\mathrm{TB}_{10.6}^{\mathrm{V}}$ & 271.7 & 274.9 & 274.0 & 274.7 & 278.0 \\
$\mathrm{~TB}_{10.6}^{\mathrm{H}}$ & 262.4 & 266.2 & 263.4 & 260.3 & 262.6 \\
$\mathrm{~TB}_{18.7}^{\mathrm{V}}$ & 253.2 & 268.0 & 275.1 & 280.3 & 283.6 \\
$\mathrm{~TB}_{18.7}^{\mathrm{H}}$ & 248.2 & 263.2 & 269.0 & 270.2 & 272.4 \\
$\mathrm{~TB}_{23.8}^{\mathrm{V}}$ & 240.2 & 258.3 & 269.8 & 279.6 & 283.5 \\
$\mathrm{~TB}_{36.6}^{\mathrm{V}}$ & 208.7 & 231.5 & 254.4 & 273.2 & 278.6 \\
$\mathrm{~TB}_{36.6}^{\mathrm{H}}$ & 205.2 & 227.8 & 250.1 & 266.1 & 270.3 \\
$\mathrm{~TB}_{89}^{\mathrm{V}}$ & 157.0 & 178.2 & 213.6 & 262.0 & 278.7 \\
$\mathrm{~TB}_{899}^{\mathrm{H}}$ & 154.3 & 174.8 & 208.6 & 257.7 & 275.2 \\
$\mathrm{~TB}_{166}^{\mathrm{V}}$ & 145.0 & 159.6 & 187.1 & 239.0 & 264.5 \\
$\mathrm{~TB}_{166}^{\mathrm{H}}$ & 141.8 & 155.6 & 181.3 & 234.9 & 263.1 \\
$\mathrm{~TB}_{183.3 \pm 3}^{\mathrm{V}}$ & 157.0 & 175.9 & 204.9 & 234.9 & 247.1 \\
$\mathrm{~TB}_{183.3 \pm 7}^{\mathrm{V}}$ & 148.1 & 164.2 & 192.7 & 235.3 & 255.4 \\
\hline
\end{tabular}

footprints. In addition, at low frequencies the emission from the surface plays a significant role in the measured radiation, which can be seen in Table 4, where substantial differences in the mean TBs for hail-contaminated profiles at different polarizations are evident, especially at the $10.6-\mathrm{GHz}$ channel. For comparison, at $36.6 \mathrm{GHz}$ the difference between channels is only $2.5 \mathrm{~K}$. Therefore, the low-frequency channels, used solitarily, are of limited use for hail detection.

\section{c. Dual-variable proxies}

A combination of two or more observables may improve the hail-detection capabilities of GPM; for example, the Ka channel can supplement the information provided by the $\mathrm{Ku}$ measurements. To fully understand the added value of the $35-\mathrm{GHz}$ channel, one should analyze its performance in combination with $\mathrm{Ku}$ data. In the same spirit, one can explore whether there is an optimal combination of GMI channels that significantly improves the effectiveness of the hail-detection routine based on radiometric data. Going even further, we may want to see whether a radar-radiometer combined algorithm has any advantage over the previously discussed single-instrument proxies.

For the sake of simplicity, our analysis is restricted to a combination of two parameters only. As opposed to the one-dimensional-setting analysis in which a single threshold on a parameter is enough to define a proxy for hail detection, in a 2D framework we need to define a region where the probability of hail is large and the number of false alarms is relatively low. Any domain shape can be used, but only regions bounded by two lines are considered here. With this constraint, the description of the domain is given by two inequalities (four parameters).

To define the optimal domain for hail detection, the 2D region is selected first, where the probability of hail occurrence oscillates between $25 \%$ and $35 \%$. Then 10 equally spaced points from this region are chosen to represent the domain. Each pair of the selected points determines the line, and all possible pairs of these lines are used as the initial guess in the optimization procedure of the CSI. We use the maximization method based on the Nelder and Mead (1965) simplex algorithm, which does not require gradient calculations. At the final iteration, the algorithm returns the pair of lines that locally maximizes the CSI. The optimal domain is then defined as the region bounded by the pair of lines that maximizes the local extrema.

Considering all combinations of observables, we found that the best-performing pair of parameters is $Z_{\mathrm{Ku}}^{\text {mix }}$ coupled with $Z_{\mathrm{Ka}}^{\mathrm{mix}}$. A full list of dual-parameter proxies whose CSI is significantly improved relative to a single-variable algorithm is shown in Tables 2-4 of the online supplemental material, stratified by instrument used. A combined use of the mixed-phase reflectivities at the $\mathrm{Ku}$ and $\mathrm{Ka}$ channels increases the CSI to $48.7 \%$ (i.e., a gain of 3.8 percentage points). There is an improvement in both the number of false alarms (a drop from $41 \%$ to $36.9 \%$ ) and in the probability of detection (a growth from $65.3 \%$ to $68 \%$ ). The additional information provided by the Ka measurement is attributed to the stronger Mie-scattering effects at higher frequency for larger hailstones relative to graupel. Moreover, hail growth requires liquid water above the freezing level, and the presence of the supercooled droplets produces significant attenuation at Ka band. Therefore, $35-\mathrm{GHz}$ reflectivity values are decreasing more quickly with range from the satellite in the presence of hail than in the presence of low-density ice. This in turn reduces $Z_{\mathrm{Ka}}^{\mathrm{mix}}$, and therefore hail is present in profiles for which $Z_{\mathrm{Ku}}^{\mathrm{mix}}$ is high but $Z_{\mathrm{Ka}}^{\mathrm{mix}}$ is relatively low (see Fig. 5a). The relation

$$
\left\{\begin{array}{l}
Z_{\mathrm{Ku}}^{\mathrm{mix}}>0.632 Z_{\mathrm{Ka}}^{\mathrm{mix}}+20.4 \\
Z_{\mathrm{Ku}}^{\mathrm{mix}}>40.15
\end{array}\right.
$$

defines the optimal proxy for hail detection using the mixed-phase reflectivity at both DPR frequencies.

Outside the Ka-band swath, the Ku-band proxies can be only improved by the TBs. In this case, the bestperforming configuration is obtained by combining $Z_{\mathrm{Ku}}^{\mathrm{mix}}$ with $\mathrm{TB}_{10.6}^{\mathrm{H}}$ or $\mathrm{TB}_{18.7}^{\mathrm{H}}$. The CSI of these couples is improved by $\sim 1$ percentage point relative to the single-parameter algorithm. Using more channels should in principle result in a better improvement of the hail-detection capabilities, but it was not tested here. The relations

$$
\left\{\begin{array}{l}
\mathrm{TB}_{10.6}^{\mathrm{H}}>-41 Z_{\mathrm{Ku}}^{\mathrm{mix}}+1896 \\
\mathrm{~TB}_{10.6}^{\mathrm{H}}<9.5 Z_{\mathrm{Ku}}^{\mathrm{mix}}+115.9
\end{array}\right.
$$

determine the region where the probability of hail occurrence is greater than about $40 \%$ (see Fig. 5b). Although the detection capabilities are lowered by 1.6 
(a)

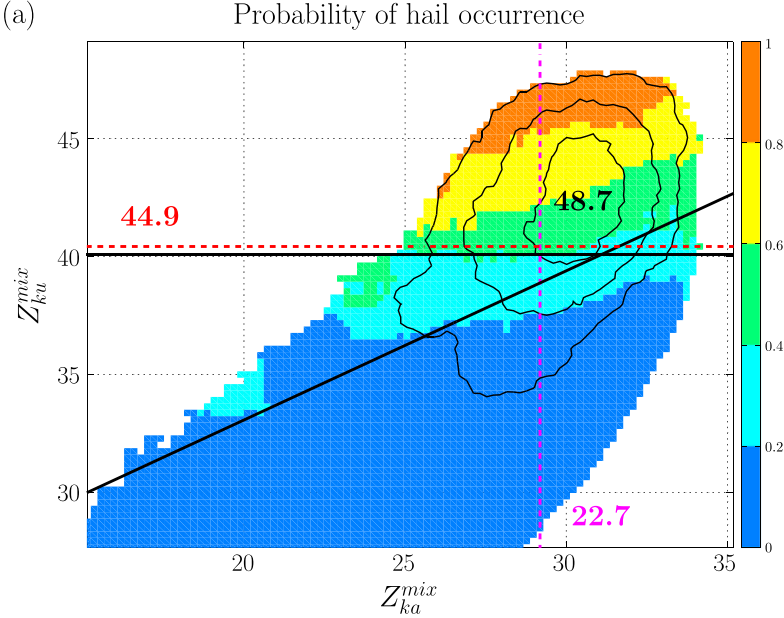

(c)

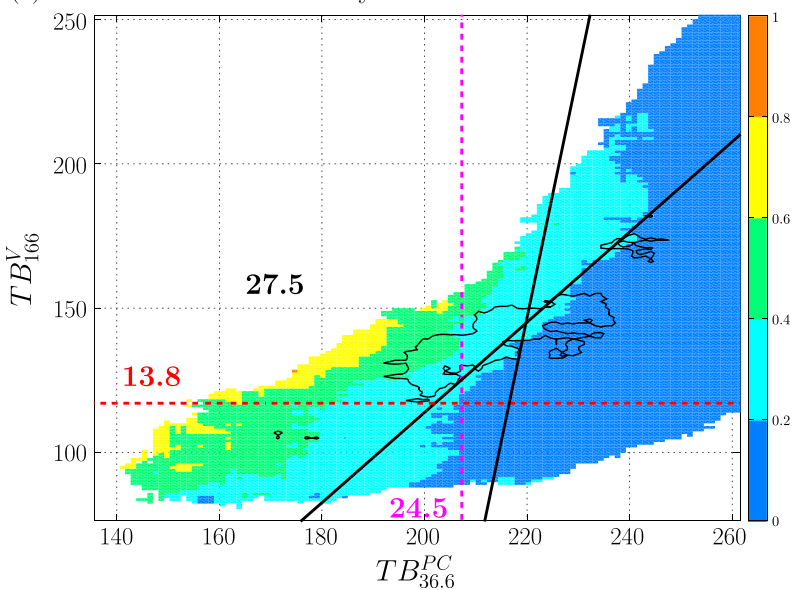

(b)

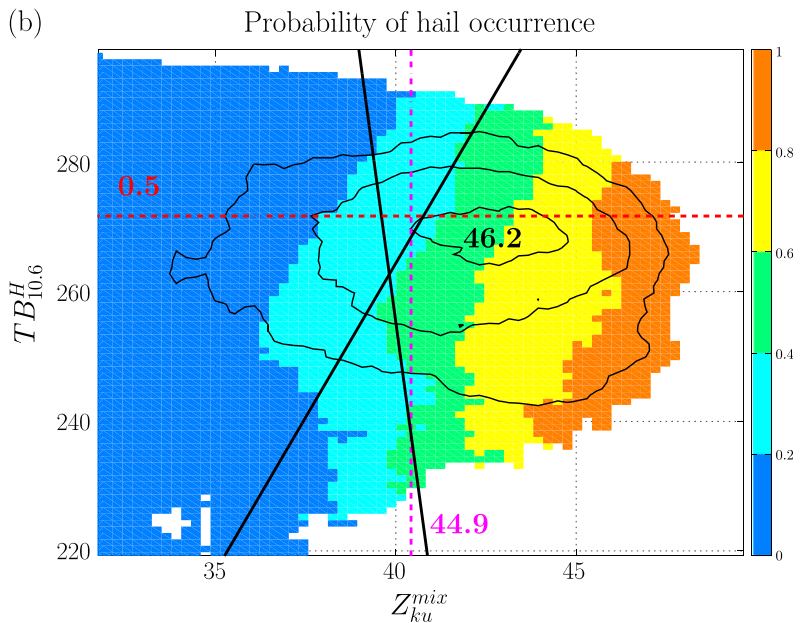

(d)

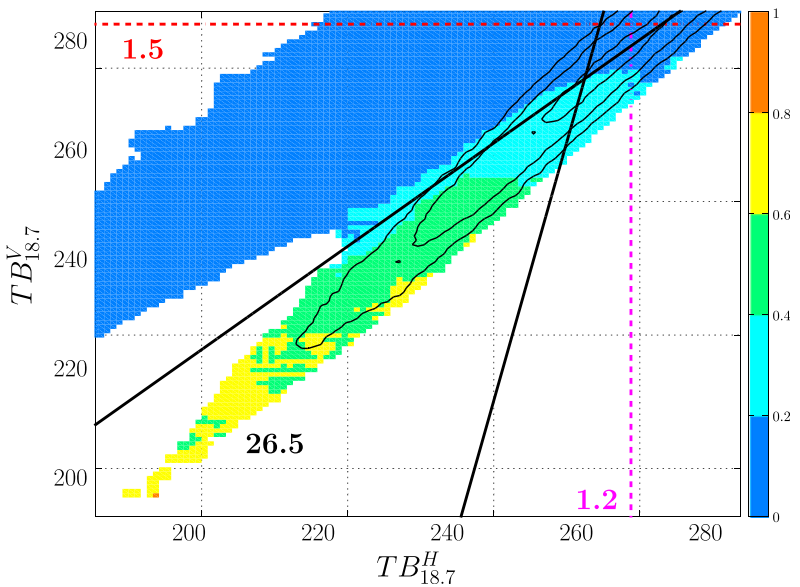

FIG. 5. The probability of hail occurrence depending on two parameters: (a) $Z_{\mathrm{Ku}}^{\mathrm{mix}}$ and $Z_{\mathrm{Ka}}^{\mathrm{mix}}$, (b) $Z_{\mathrm{Ku}}^{\mathrm{mix}}$ and $\mathrm{TB}_{10.6}^{\mathrm{H}}$, (c) $\mathrm{TB}_{36.6}^{\mathrm{PC}}$ and $\mathrm{TB}_{166}^{\mathrm{V}}$, and (d) $\mathrm{TB}_{18.7}^{\mathrm{H}}$ and $\mathrm{TB}_{18.7}^{\mathrm{V}}$. Thick black lines mark the boundary of the region that maximizes the CSI. Dashed lines mark the proxies in a singleparameter setting, and the numbers in the same color denote the CSI of each single-parameter proxy. Black numbers correspond to the CSI value of the dual-variable algorithm. Thin black contour lines show the domain of measurements associated with $2 \%, 5 \%$, and $10 \%$ of all hail occurrences.

percentage points, the dual-variable algorithm reduces the number of false alarms, mainly associated with warm TBs. Similar improvements are also observed when $Z_{\mathrm{Ku}}^{\mathrm{mix}}$ is combined with the high-frequency TBs (not shown).

A combination of two TBs brings improvement in the CSI that is similar to that of the case of two radar observables. The highest CSI is obtained when $\mathrm{TB}_{36.6}^{\mathrm{PC}}$ observations are supplemented by high-frequency measurements at the 166-GHz channel (Fig. 5c). In this case, hail is observed not only when both TBs are very low but also when low values of $\mathrm{TB}_{36.6}^{\mathrm{PC}}$ are observed with relatively high values of $\mathrm{TB}_{166}^{\mathrm{V}}$. This phenomenon is driven by the behavior of the scattering parameters at different frequencies. The extinction coefficient, which controls how much radiation coming from the warm underlying layers is scattered away from the radiometer, reaches the maximum value for a certain hydrometeor size (Fig. 6b).
It grows for small diameters, reaches the maximum value, and then decreases with the increasing size. For example, at $166 \mathrm{GHz}$ the strongest extinction occurs for $1.3-\mathrm{mm}$ hailstones and is nearly 3 times as strong as for $5-\mathrm{mm}$ stones. In addition, the single-scattering albedo $\omega$ behaves in a similar way and reaches the maximum value for a certain size that decreases with frequency, which may be seen in Fig. 6a. All of these factors imply that, at short wavelengths, big hailstones may be associated with warmer TBs. Our analysis showed that the maximum CSI $(27.5 \%)$ of hail detection is obtained when

$$
\begin{cases}\mathrm{TB}_{166}^{\mathrm{V}}>1.563 \mathrm{~TB}_{36.6}^{\mathrm{PC}}-198.8 \\ \mathrm{~TB}_{166}^{\mathrm{V}}>8.538 \mathrm{~TB}_{36.6}^{\mathrm{PC}}-1731.7\end{cases}
$$

which corresponds to $59.4 \%$ of false alarms and $46 \%$ of detected hail storms. Similar behavior is observed when 

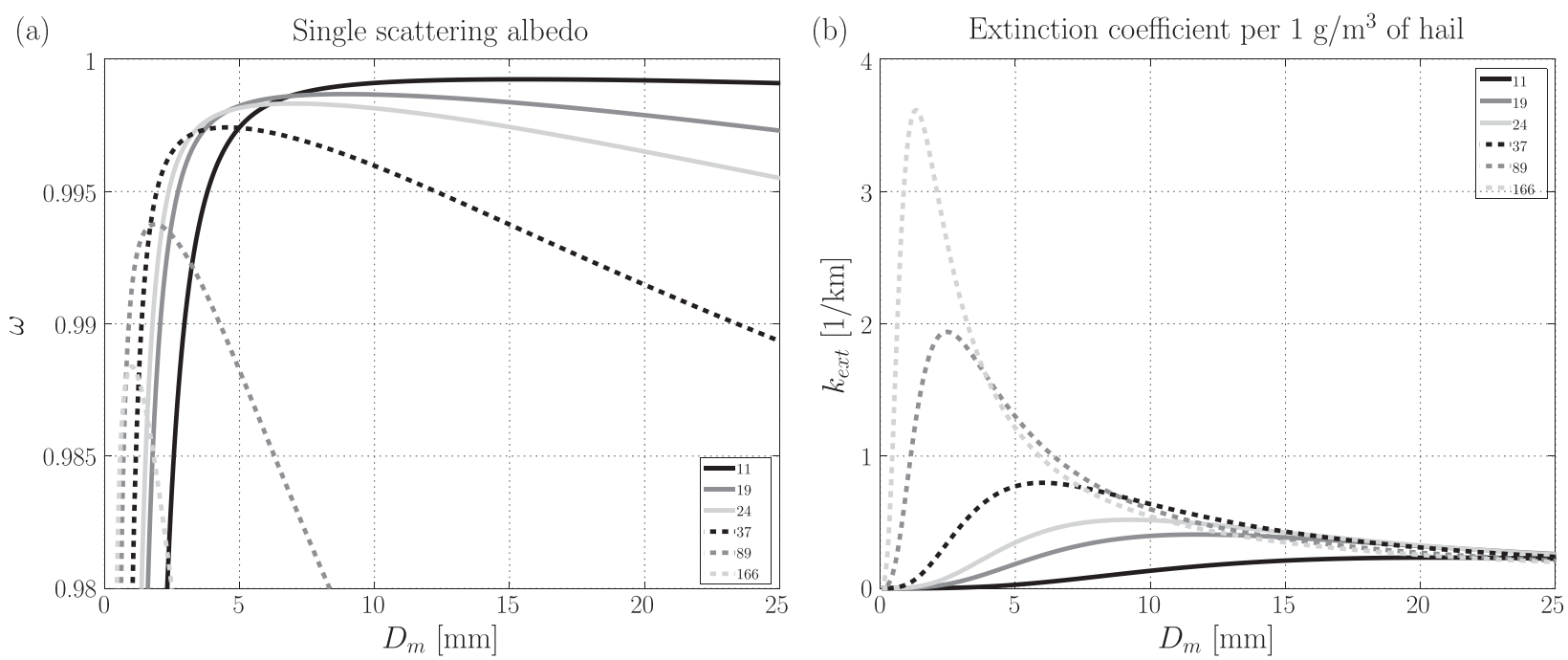

FIG. 6. The (a) single-scattering albedo and (b) extinction coefficient of spherical hailstones as a function of the diameter at the GMI frequencies.

the observations at $183.3 \pm 7$ and $183.3 \pm 3 \mathrm{GHz}$ are used together with $\mathrm{TB}_{36.6}^{\mathrm{PC}}$.

Because there is no formula in the literature for polarization-corrected temperature at the 10.6- and 18.7-GHz channels, we checked whether vertical and horizontal measurements at these frequencies used together provide some information on hail presence. Although $\mathrm{TB}_{18.7}^{\mathrm{V}}$ alone has very low skills for detecting high-density ice (CSI of $1.5 \%$ ), it shows some potential when it is used in combination with the horizontal channel. Figure $5 \mathrm{~d}$ shows that only both channels together are able to distinguish hail from other hydrometeor types or from the surface signal. With the relation

$$
\left\{\begin{array}{l}
\mathrm{TB}_{18.7}^{\mathrm{V}}<0.773 \mathrm{~TB}_{18.7}^{\mathrm{H}}+63.1 \\
\mathrm{~TB}_{18.7}^{\mathrm{V}}>3.874 \mathrm{~TB}_{18.7}^{\mathrm{H}}-719.5
\end{array}\right.
$$

we obtained a CSI of $26.5 \%$, which is the best score among all single-frequency radiometer-based proxies. Notice that the first condition on $\mathrm{TB}_{18.7}^{\mathrm{V}}$ restricts the space of possible TBs to those with small polarization differences, whereas the second condition gives the optimal range of TBs associated with hail. The behavior of the $\mathrm{PDF}$, that is, a decrease with an increasing polarization difference, suggests that the polarization-corrected temperature at $18.7 \mathrm{GHz}$ can be successfully defined. For defining a single-variable algorithm based on the TB at 18.7 GHz we used the preliminary formula

$$
\mathrm{TB}_{18.7}^{\mathrm{PC}}=2.38 \mathrm{~TB}_{18.7}^{\mathrm{V}}-1.38 \mathrm{~TB}_{18.7}^{\mathrm{H}},
$$

suggested by T. Chronis (2016, personal communication). The PDF of hail occurrence associated with $\mathrm{TB}_{18.7}^{\mathrm{PC}}$ is equal to 1 for $\mathrm{TB}_{18.7}^{\mathrm{PC}}<200$ and decreases to 0 for $\mathrm{TB}_{18.7}^{\mathrm{PC}}>280$. It compares well to results presented by Cecil (2009), where the correlation between hail reports and the minimal value of $\mathrm{TB}_{18.7}^{\mathrm{V}}$ within the storm extent was assessed. The proxy value of $260 \mathrm{~K}$ defines the algorithm with a CSI of $25.7 \%(\mathrm{FAR}=62.2 \%$; POD $=44.7 \%)$.

The findings of our study support a new application of 18.7-GHz measurements. This channel not only can be successfully used to estimate total water content over a radiometrically cold background but may also be employed in hail detection. The novel capability of this measurement can be due to the improved resolution of the GMI relative to other radiometers (e.g., the footprint of the $19-\mathrm{GHz}$ channel of the TRMM Microwave Imager was $35 \mathrm{~km} \times$ $21 \mathrm{~km}$, whereas the GMI performs the same frequency measurements with a resolution of $18.1 \mathrm{~km} \times 10.9 \mathrm{~km}$ ).

For 10.6-GHz channels, the peak of the PDF of hail occurrence in the $\mathrm{TB}_{10.6}^{\mathrm{V}} \times \mathrm{TB}_{10.6}^{\mathrm{H}}$ plane is not as well pronounced in terms of a magnitude and extent as it is for 18.7-GHz measurements (not shown). The boundary lines do not appropriately separate hail from the other species, and the algorithm based on the vertical and horizontal polarization channels at $10.6 \mathrm{GHz}$ has a CSI of only $10.1 \%$. As can be seen in Table 4 , there is only a small difference in the mean TB for all considered hydrometeor types. The horizontal measurements oscillate around $265 \mathrm{~K}$, whereas the vertical-channel observations are between 270 and $280 \mathrm{~K}$ for all considered species.

\section{Applications}

The proxies that were previously derived can be used to present a global distribution of extreme-weather 
events on the basis of GPM observables. The terms "extreme" and "severe" are used here in the context of the presence of hail of any size anywhere in the vertical column.

The PDF of hail occurrence depending on $Z_{\mathrm{Ku}}^{\mathrm{mix}}$ is used to produce a map of extreme weather events. Oneparameter proxy is used to maximize a sample size, because the Ku-band swath is almost 2 times the swath width of Ka band. Note that this hail-detection proxy was developed using data from land-based convective storms over the continental United States. Nevertheless, we decided to apply this proxy to other regions and marine environments because a very similar parameter was already used by Cecil (2011) for a regional scaling of the TBs. Two years of the DPR data from April 2014 to the end of March 2016 are analyzed. The global distribution of the frequency of hail occurrence is calculated by adopting the following steps:

1) For each DPR vertical profile, the probability of hail occurrence is assigned on the basis of the PDF produced for $Z_{\mathrm{Ku}}^{\mathrm{mix}}$ observations.

2) The calculated probabilities are grouped according to the location of the measurement in each $3^{\circ} \times 3^{\circ}$ box.

3) The hail probabilities are summed and then divided by the total number of the DPR profiles within each grid box.

The resulting map of the hail frequency is shown in Fig. 7a. The majority of extreme events occur over land and over regions adjacent to the land, which was already observed by Orville and Henderson (1986). The spatial patterns of DPR profiles with hail in Fig. 7a are generally consistent with previous satellite-based estimates of severe-thunderstorm locations (Cecil and Blankenship 2012; Ferraro et al. 2015) and reanalysis-based identification of likely severe-thunderstorm environments (Brooks et al. 2003, their Figs. 17-18). Many of the same regions having local maxima (e.g., equatorial Africa, the subtropical Americas, Pakistan, and Bangladesh) are noted in nearly all such studies. Despite that, some differences are noticeable, for example, the region of severe weather in North America extends to around $48^{\circ} \mathrm{N}$, which is about $5^{\circ}$ farther north than was shown by Cecil and Blankenship (2012). Moreover, the regional scaling of the TB at $36.6 \mathrm{GHz}$ proposed by the same authors results in a great reduction in the frequency of hail occurrence in central Africa $\left(20^{\circ}-33^{\circ} \mathrm{E}\right)$, whereas our analysis suggests that the hail intensity there is comparable to that observed in Tornado Alley in the United States. The study of Cecil and Blankenship (2012) aims at detecting storms that are related to the hailfall at the ground, whereas the analysis here is directed at the identification of hail aloft, which can melt before reaching the surface, especially in tropical storms. Figure 7a does not necessarily imply the occurrence of severe weather at the surface; central Africa and northwestern South America are both known to have exceedingly high annual mean lightning-flash rates (Cecil et al. 2014, and many others), which would be consistent with frequent occurrences of hail aloft. However, relatively fewer storms in central Africa and northwestern South America are expected on the basis of the severe-storm environments that Brooks et al. (2003) and the rest of the very limited literature report on from the ground.

We also compared our results in the United States with the high-resolution severe-hailfall climatology derived by Cintineo et al. (2012) from the multiradar multisensor algorithm. Their study was based on localizing regions where the maximum expected size of hail was greater than $29 \mathrm{~mm}$ and the extent of this region was greater than $5 \mathrm{~km}^{2}$. Overall, there is a good agreement in these two datasets, the main difference being an overestimate of a number of hail events in regions over the western part of the Gulf of Mexico for our algorithm, which suggests that storms there either tend to be more isolated or are associated with nonsevere hailfalls.

Besides already mentioned locations, there are also smaller regions where the hail frequency is large such as the eastern shore of India, the southern slope of the Himalayas, South Africa, Indochina, or the northern coast of the Yellow Sea. It reflects well the findings of Brooks et al. (2003), who showed that in all of these locations the frequency of environments supportive of severe convection is high. In Europe we observe moderate hail intensity decreasing with increasing latitudes. Several hail storms are scattered over high latitudes in Eurasia and North America. The strip of enhanced storm occurrence across much of Russia in Fig. 7a is consistent with a strip of enhanced tornado environments depicted by Brooks et al. (2003). Further analysis of the particular environmental conditions contributing to storm occurrence in each of these regions is worthy of its own study and is not attempted here.

Note that there is almost no hail activity for high latitudes in the Southern Hemisphere. It was already noticed by Zipser et al. (2006) that marine storms are less intense and that low hail intensity in the Southern Hemisphere is likely the result of a lower land fraction. There are only a few regions over the oceans that are strongly affected by severe weather, and they are typically on the eastern side of continents, for example, off the coast of Argentina, South Africa, and Australia.

For locations where the hail-occurrence frequency is greater than $0.001 \%$, the mean date of the hailstorm season is calculated (Fig. 7b). Although only two years of data 

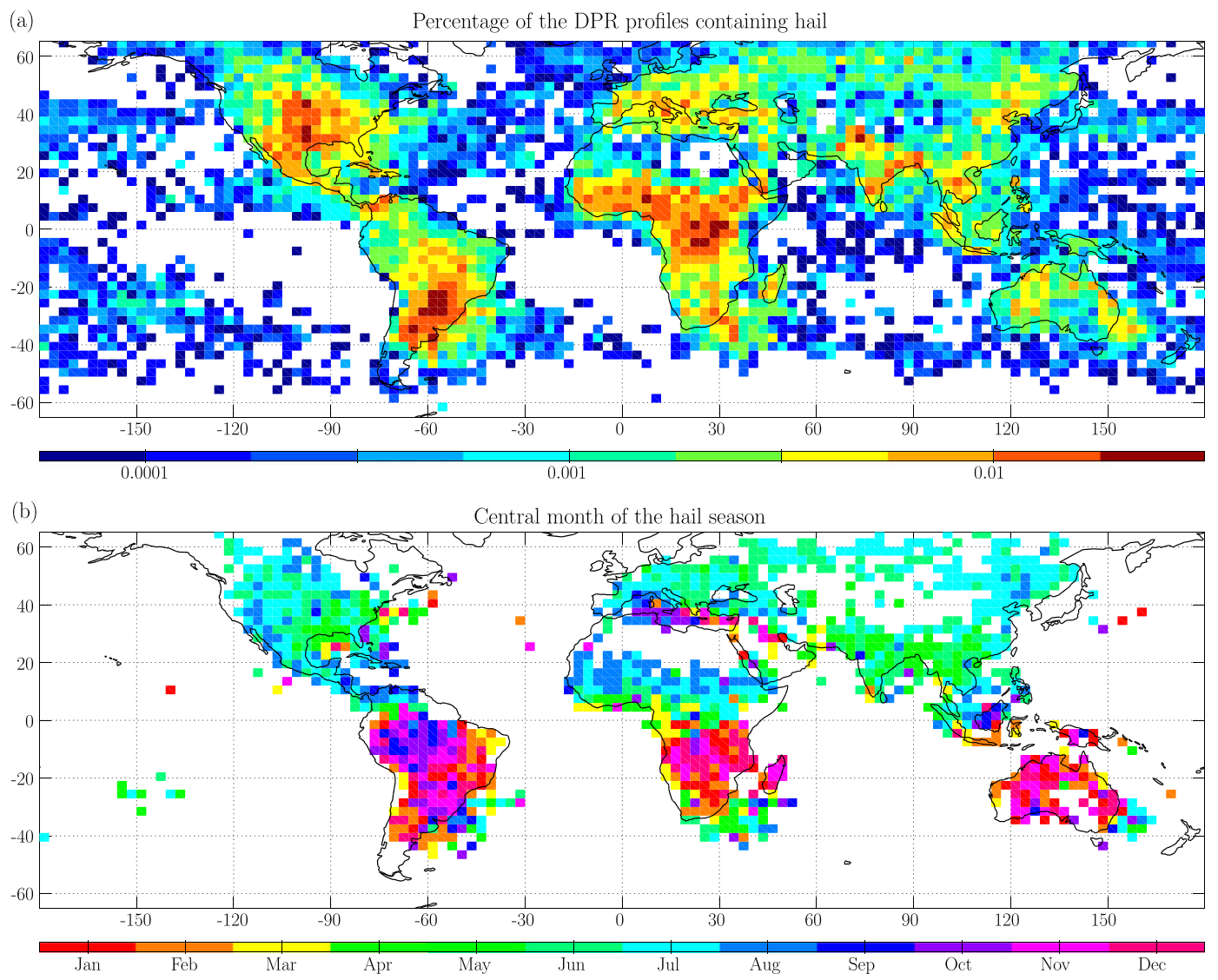

FIG. 7. Global maps of (a) the fraction of the DPR profiles that contain hail, based on the $Z_{\mathrm{Ku}}^{\mathrm{mix}}$ proxy and (b) the expected hailstorm date.

were used, our results compare well to hail-occurrence maps presented in Cecil and Blankenship (2012), and a clear seasonal pattern is evident. Severe weather over land is observed mostly during the warm season, that is, May-July in the Northern Hemisphere and NovemberJanuary in the Southern Hemisphere. Marine hailstorms do not obey this rule; for example, the offshore region of southern Africa or Australia is affected by extreme weather mostly during winter. There is also a noticeable time shift toward the autumn months for hailstorm occurrence over the Mediterranean Sea relative to continental storms. The most apparent discrepancy between our results and those of Cecil and Blankenship (2012) is present offshore of Australia where storms occur at least 2 months earlier according to our analysis. This difference might be due to a year-to-year weather variability that affects short-term results.

The diurnal cycle of extreme storms is presented in Fig. 8. For this study, Earth is divided into three geographical zones: a $30^{\circ}$ strip around the equator, latitudes north of $15^{\circ} \mathrm{N}$, and latitudes south of $15^{\circ} \mathrm{S}$. For all of these regions a strong peak around 1500 local solar time and a local minimum at 1000 local solar time are evident over land, whereas over ocean a broad nocturnal maximum is present. It has already been observed by Zipser et al. (2006) for tropical storms, and now with the broader coverage of GPM we can confirm it in the other climatological zones. The width of the peak of hail intensity for the considered regions is nearly the same and is equal to around $10 \mathrm{~h}$. The diurnal cycle over land in the southern part of the globe is a little bit noisy, but this might be attributed to a small land fraction.

\section{Summary}

The main purpose of this analysis is to identify the signatures of hail in terms of active and passive measurements provided by the suite of sensors on board the Global Precipitation Measurement Core Observatory satellite. Ground-based dual-polarimetric radar data are compared with the GPM mission observables collected from April 2014 to June 2016.

A detailed analysis of more than 20 GPM observables showed that the parameters related to the $\mathrm{Ku}$ radar 


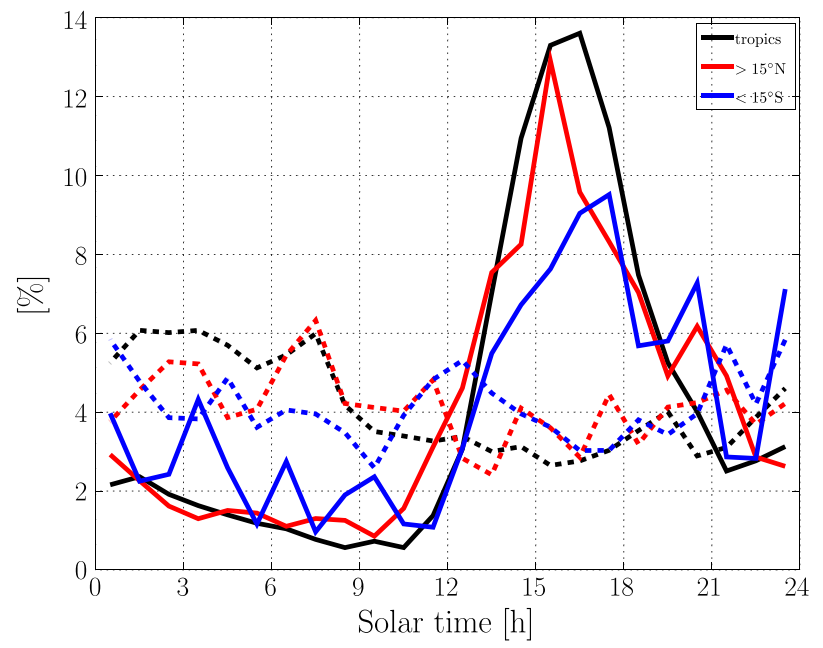

FIG. 8. Diurnal cycle of hail occurrence based on the $Z_{\mathrm{Ku}}^{\operatorname{mix}}$ proxy. The distribution is broken out by land (solid lines) and ocean (dashed lines) for three geographical zones: the tropics, latitudes $>$ $15^{\circ} \mathrm{N}$, and latitudes $<15^{\circ} \mathrm{S}$.

reflectivity factor are the best-performing hail indicators. Three Ku-band observables (the column-integrated reflectivity, the mean reflectivity in the mixed-phase layer, and the $40-\mathrm{dBZ} \mathrm{Ku}$ reflectivity-level height above the $0^{\circ}$ isotherm) reached a critical success index of $42 \%-45 \%$.

When considering the CSI, the efficiency of Ka-band proxies is lower by at least 10 percentage points relative to the $\mathrm{Ku}$ proxies, even when the radar reflectivity factor corrected for attenuation is used. Hydrometeor species whose diameter is comparable to or larger than the wavelength of Ka radiation $(8 \mathrm{~mm})$ scatter the Ka signal according to Mie theory; therefore, the presence of big hailstones does not produce a significant enhancement in radar reflectivity, thus making them difficult to detect.

The hail-detection algorithms based on the dualwavelength-ratio proxies do not perform better than the one exploiting Ka-band observables only. This suggests that the DWR is mainly driven by the differential attenuation and not by differences in backscattering properties. The use of the reflectivity values corrected for attenuation does not improve hail-detection capabilities of the DWR proxies, which strongly suggests that there is a high degree of uncertainty in the attenuation correction of the Ka reflectivity when high-density ice is present in the column. Additional ambiguities in the DWR profiles are caused by multiple-scattering effects (Battaglia et al. 2014, 2016) and by nonuniform beamfilling effects (Tanelli et al. 2012).

The proxies based on passive measurements perform worse than those based on radar data. Two of the radiometer-based hail-detection algorithms perform with a comparable CSI $(24 \%-26 \%)$. One of them uses the PCT at $36.6 \mathrm{GHz}$, with the optimal threshold value of $207 \mathrm{~K}$. The second one is based on measurements at 18.7 GHz. Using a preliminary formula for PCT at this frequency, the proxy value of $261 \mathrm{~K}$ defines the optimal hail-detection algorithm for the 18.7-GHz channel.

A dual-variable approach improves the hail-detection capabilities by 3.8 percentage points. The combination involving the mixed-phase reflectivity at both $\mathrm{Ku}$ and $\mathrm{Ka}$ bands exhibits a CSI of $49 \%$. This algorithm is applicable only in the inner swath of the DPR, however. Activepassive methods do not change notably the hail-detection capabilities of the $\mathrm{Ku}$ channel, but the information provided by the radiometer helps to reduce the number of false alarms. Outside the DPR swath, passive measurements at $36.6 \mathrm{GHz}$ supplemented by $166-\mathrm{GHz}$ channel have the greatest ability to detect hail (CSI of $27.5 \%$ ).

Ongoing work is focused on identifying hailcontaminated profiles in the GMI field of view by fully accounting for the slanted geometry of the measurements, without the use of any parallax-correction techniques or the need for any deconvolution methods. This promises to further improve hail-detection capabilities of the passive instrument on board the GPM mission satellite. We also encourage in-depth studies on the PCT at $18.7 \mathrm{GHz}$, which has a great potential for extreme-weather detection.

Acknowledgments. This research used the SPECTRE High Performance Computing Facility at the University of Leicester. NEXRAD data were obtained from the National Oceanic and Atmospheric Administration via Amazon Web Services (https://aws.amazon.com/noaa-bigdata/nexrad/). NEXRAD data were ingested, edited, and analyzed using the following open-source packages: PyART (http://arm-doe.github.io/pyart/), CSU_RadarTools (https://github.com/CSU-Radarmet/CSU_RadarTools), DualPol (https://github.com/nasa/DualPol), SkewT (https:// pypi.python.org/pypi/SkewT), and ARTview (https:// github.com/nguy/artview). Timothy Lang was funded by the GPM Ground Validation program, under the direction of Mathew Schwaller and Ramesh Kakar of the National Aeronautics and Space Administration. Daniel Cecil was funded by the NASA Precipitation Measurement Missions Science Team. Level-2 V04A-GPM data were downloaded from the Precipitation Processing System. The work done by A. Battaglia and F. Tridon was funded by the project Calibration and Validation Studies over the North Atlantic and UK for the Global Precipitation Measurement mission funded by the UK NERC (NE/L007169/1). The work by Simone Tanelli was performed at the Jet Propulsion Laboratory, California Institute of Technology, under contract with the National Aeronautics and Space Administration. Support from the Precipitation Measurement Missions and Cloud and 
Radiation Programs is gratefully acknowledged. We are grateful to Dr. Brenda Dolan for expertise that she provided regarding the hydrometeor-identification algorithm.

\section{REFERENCES}

Auer, A. H., Jr., 1994: Hail recognition through the combined use of radar reflectivity and cloud-top temperatures. Mon. Wea. Rev., 122, 2218-2221, doi:10.1175/1520-0493(1994)122<2218: HRTTCU>2.0.CO;2.

Battaglia, A., S. Tanelli, G. M. Heymsfield, and L. Tian, 2014: The dual wavelength ratio knee: A signature of multiple scattering in airborne Ku-Ka observations. J. Appl. Meteor. Climatol., 53, 1790-1808, doi:10.1175/JAMC-D-13-0341.1.

, K. Mroz, S. Tanelli, F. Tridon, and P.-E. Kirstetter, 2016: Multiple-scattering-induced ghost echoes in GPM DPR observations of a tornadic supercell. J. Appl. Meteor. Climatol., 55, 1653-1666, doi:10.1175/JAMC-D-15-0136.1.

Brooks, H. E., J. W. Lee, and J. P. Craven, 2003: The spatial distribution of severe thunderstorm and tornado environments from global reanalysis data. Atmos. Res., 67-68, 73-94, doi:10.1016/ S0169-8095(03)00045-0.

Cecil, D. J., 2009: Passive microwave brightness temperatures as proxies for hailstorms. J. Appl. Meteor. Climatol., 48, 1281-1286, doi:10.1175/2009JAMC2125.1.

, 2011: Relating passive 37-GHz scattering to radar profiles in strong convection. J. Appl. Meteor. Climatol., 50, 233-240, doi:10.1175/2010JAMC2506.1.

— severe hailstorms as estimated by satellite passive microwave imagers. J. Climate, 25, 687-703, doi:10.1175/ JCLI-D-11-00130.1.

—_, E. J. Zipser, and S. W. Nesbitt, 2002: Reflectivity, ice scattering, and lightning characteristics of hurricane eyewalls and rainbands. Part I: Quantitative description. Mon. Wea. Rev., 130, 769-784, doi:10.1175/1520-0493(2002)130<0769: RISALC $>2.0 . \mathrm{CO} ; 2$.

—_, D. E. Buechler, and R. J. Blakeslee, 2014: Gridded lightning climatology from TRMM-LIS and OTD: Dataset description. Atmos. Res., 135-136, 404-414, doi:10.1016/ j.atmosres.2012.06.028.

Cintineo, J. L., T. M. Smith, V. Lakshmanan, H. E. Brooks, and K. L. Ortega, 2012: An objective high-resolution hail climatology of the contiguous United States. Wea. Forecasting, 27, 1235-1248, doi:10.1175/WAF-D-11-00151.1.

Depue, T. K., P. C. Kennedy, and S. A. Rutledge, 2007: Performance of the hail differential reflectivity $\left(H_{\mathrm{DR}}\right)$ polarimetric radar hail indicator. J. Appl. Meteor. Climatol., 46, 1290-1301, doi:10.1175/JAM2529.1.

Dolan, B., and S. A. Rutledge, 2009: A theory-based hydrometeor identification algorithm for X-band polarimetric radars. J. Atmos. Oceanic Technol., 26, 2071-2088, doi:10.1175/ 2009JTECHA1208.1.

,,-- S. Lim, V. Chandrasekar, and M. Thurai, 2013: A robust C-band hydrometeor identification algorithm and application to a long-term polarimetric radar dataset. J. Appl. Meteor. Climatol., 52, 2162-2186, doi:10.1175/JAMC-D-12-0275.1.

Donaldson, R. J., Jr., 1959: Analysis of severe convective storms observed by radar-II. J. Meteor., 16, 281-287, doi:10.1175/ 1520-0469(1959)016<0281:AOSCSO > 2.0.CO;2.

Doswell, C. A., III, H. E. Brooks, and M. P. Kay, 2005: Climatological estimates of daily local nontornadic severe thunder- storm probability for the United States. Wea. Forecasting, 20, 577-595, doi:10.1175/WAF866.1.

Ferraro, R., J. Beauchamp, D. J. Cecil, and G. Heymsfield, 2015: A prototype hail detection algorithm and hail climatology developed with the Advanced Microwave Sounding Unit (AMSU). Atmos. Res., 163, 24-35, doi:10.1016/j.atmosres.2014.08.010.

Grecu, M., W. S. Olson, S. J. Munchak, S. Ringerud, L. Liao, Z. Haddad, B. L. Kelley, and S. F. McLaughlin, 2016: The GPM combined algorithm. J. Atmos. Oceanic Technol., 33, 2225-2245, doi:10.1175/JTECH-D-16-0019.1.

Heinselman, P. L., and A. V. Ryzhkov, 2006: Validation of polarimetric hail detection. Wea. Forecasting, 21, 839-850, doi:10.1175/WAF956.1.

Helmus, J. J., and S. M. Collis, 2016: The Python ARM Radar Toolkit (Py-ART), a library for working with weather radar data in the Python programming language. J. Open Res. Software, 4, e25, doi:10.5334/jors.119.

Heymsfield, A. J., 1978: The characteristics of graupel particles in northeastern Colorado cumulus congestus clouds. J. Atmos. Sci., 35, 284-295, doi:10.1175/1520-0469(1978)035<0284: TCOGPI $>2.0 . \mathrm{CO} ; 2$.

— , and R. Wright, 2014: Graupel and hail terminal velocities: Does a "supercritical" Reynolds number apply? J. Atmos. Sci., 71, 3392-3403, doi:10.1175/JAS-D-14-0034.1.

Hou, A. Y., and Coauthors, 2014: The Global Precipitation Measurement mission. Bull. Amer. Meteor. Soc., 95, 701-722, doi:10.1175/BAMS-D-13-00164.1.

Kitzmiller, D. H., W. E. McGovern, and R. F. Saffle, 1995: The WSR-88D severe weather potential algorithm. Wea. Forecasting, 10, 141-159, doi:10.1175/1520-0434(1995)010<0141: TWSWPA $>2.0 . \mathrm{CO} ; 2$.

Lang, T. J., D. A. Ahijevych, S. W. Nesbitt, R. E. Carbone, S. A. Rutledge, and R. Cifelli, 2007: Radar-observed characteristics of precipitating systems during NAME 2004. J. Climate, 20 , 1713-1733, doi:10.1175/JCLI4082.1.

Leppert, K. D., II, and D. J. Cecil, 2015: Signatures of hydrometeor species from airborne passive microwave data for frequencies 10-183 GHz. J. Appl. Meteor. Climatol., 54, 1313-1334, doi:10.1175/JAMC-D-14-0145.1.

Liu, C., E. J. Zipser, D. J. Cecil, S. W. Nesbitt, and S. Sherwood, 2008: A cloud and precipitation feature database from nine years of TRMM observations. J. Appl. Meteor. Climatol., 47, 2712-2728, doi:10.1175/2008JAMC1890.1.

Mugnai, A., E. A. Smith, and G. J. Tripoli, 1993: Foundations for statistical-physical precipitation retrieval from passive microwave satellite measurements. Part II: Emission-source and generalized weighting-function properties of a time-dependent cloud-radiation model. J. Appl. Meteor., 32, 17-39, doi:10.1175/ 1520-0450(1993)032<0017:FFSPRF $>2.0 . C O ; 2$.

Musil, D. J., S. A. Christopher, R. A. Deola, and P. L. Smith, 1991: Some interior observations of southeastern Montana hailstorms. J. Appl. Meteor., 30, 1596-1612, doi:10.1175/ 1520-0450(1991)030<1596:SIOOSM > 2.0.CO;2.

Nelder, J. A., and R. Mead, 1965: A simplex method for function minimization. Comput. J., 7, 308, doi:10.1093/comjnl/7.4.308.

Nesbitt, S. W., E. J. Zipser, and D. J. Cecil, 2000: A census of precipitation features in the tropics using TRMM: Radar, ice scattering, and lightning observations. J. Climate, 13, 4087-4106, doi:10.1175/1520-0442(2000)013<4087:ACOPFI>2.0.CO;2.

Ortega, K. L., T. M. Smith, K. L. Manross, A. G. Kolodziej, K. A. Scharfenberg, A. Witt, and J. J. Gourley, 2009: The Severe Hazards Analysis and Verification Experiment. Bull. Amer. Meteor. Soc., 90, 1519-1530, doi:10.1175/2009BAMS2815.1. 
, J. M. Krause, and A. V. Ryzhkov, 2016: Polarimetric radar characteristics of melting hail. Part III: Validation of the algorithm for hail size discrimination. J. Appl. Meteor. Climatol., 55, 829848, doi:10.1175/JAMC-D-15-0203.1.

Orville, R. E., and R. W. Henderson, 1986: Global distribution of midnight lightning: September 1977 to August 1978. Mon. Wea. Rev., 114, 2640-2653, doi:10.1175/1520-0493(1986)114<2640: GDOMLS $>2.0 . \mathrm{CO} ; 2$.

Schaefer, J. T., 1990: The critical success index as an indicator of warning skill. Wea. Forecasting, 5, 570-575, doi:10.1175/ 1520-0434(1990)005<0570:TCSIAA > 2.0.CO;2.

Spencer, R. W., H. M. Goodman, and R. E. Hood, 1989: Precipitation retrieval over land and ocean with the SSM/I: Identification and characteristics of the scattering signal. J. Atmos. Oceanic Technol., 6, 254-273, doi:10.1175/1520-0426(1989)006<0254: PROLAO $>2.0 . \mathrm{CO} ; 2$.

Stephens, G. L., and Coauthors, 2002: The CloudSat mission and the A-Train: A new dimension of space-based observations of clouds and precipitation. Bull. Amer. Meteor. Soc., 83, 17711790, doi:10.1175/BAMS-83-12-1771.
Stogryn, A., 1978: Estimates of brightness temperatures from scanning radiometer data. IEEE Trans. Antennas Propag., 26, 720-726, doi:10.1109/TAP.1978.1141919.

Tanelli, S., G. F. Sacco, S. L. Durden, and Z. S. Haddad, 2012: Impact of non-uniform beam filling on spaceborne cloud and precipitation radar retrieval algorithms. Remote Sensing of the Atmosphere, Clouds, and Precipitation IV, T. Hayasaka, K. Nakamura, and E. Im, Eds., International Society for Optical Engineering (SPIE Proceedings, Vol. 8523), doi:10.1117/12.977375.

Waldvogel, A., B. Federer, and P. Grimm, 1979: Criteria for the detection of hail cells. J. Appl. Meteor., 18, 1521-1525, doi:10.1175/ 1520-0450(1979)018<1521:CFTDOH > 2.0.CO;2.

Witt, A., M. D. Eilts, G. J. Stumpf, J. T. Johnson, E. D. W. Mitchell, and K. W. Thomas, 1998: An enhanced hail detection algorithm for the WSR-88D. Wea. Forecasting, 13, 286-303, doi:10.1175/1520-0434(1998)013<0286:AEHDAF $>2.0$. $\mathrm{CO} ; 2$

Zipser, E. J., C. Liu, D. J. Cecil, S. W. Nesbitt, and D. P. Yorty, 2006: Where are the most intense thunderstorms on Earth? Bull. Amer. Meteor. Soc., 87, 1057-1071, doi:10.1175/BAMS-87-8-1057. 